University of Zurich

Department of Economics

Working Paper Series

ISSN 1664-7041 (print)

ISSN 1664-705X (online)

Working Paper No. 234

\title{
Mental Capabilities, Trading Styles, and Asset Market Bubbles: Theory and Experiment
}

Andreas Hefti, Steve Heinke and Frédéric Schneider

August 2016 


\title{
Mental Capabilities, Trading Styles, and Asset Market Bubbles
}

\author{
Theory and Experiment
}

\author{
Andreas Hefti* $\quad$ Steve Heinke ${ }^{\dagger} \quad$ Frédéric Schneider ${ }^{\ddagger}$
}

August 30, 2016

\begin{abstract}
We propose that heterogeneous asset trading behavior is the result of two distinct, non-convertible mental dimensions: analytical ("quantitative") capability and mentalizing ("perspective-taking") capability. We develop a framework of mental capabilities that yields testable predictions about individual trading behavior, revenue distribution and aggregate outcomes. The two-dimensional structure of mental capabilities predicts the existence of four mental types with distinguishable trading patterns and revenues. Individuals will trade most successfully if and only if they have both capabilities. On the other hand, subjects who can mentalize well but have poor analytical capability will suffer the largest losses. As a consequence, being able in just one dimension does not assure trading success. We test these implications in a laboratory environment, where we first independently elicit subjects' capabilities in both dimensions and then conduct a standard asset market experiment. We find that individual trading gains and patterns are consistent with our theoretical predictions. Our results suggest that two mental dimensions are necessary to encompass the complex heterogeneous behaviors in asset markets; a one-dimensional measure of mental capability will lead to biased conclusions. The findings have potential implications for financial institutions, which can use the measures to select successful traders, or for policy-makers, helping them to prevent the formation of asset bubbles. Finally, our conceptual framework and the empirical screening method could be applied to explain heterogeneous behavior in other games.
\end{abstract}

Key words: Asset Markets; Heterogeneity; Mental Capabilities

JEL-Codes: G02, C92

${ }^{*}$ Department of Economics, University of Zürich and School of Management and Law, Zurich University of Applied Sciences, andreas.hefti@econ.uzh.ch

${ }^{\dagger}$ Department of Economics, University of Zürich, steve.heinke@econ.uzh.ch

${ }^{\ddagger}$ School of Management, Yale University, frederic.schneider@yale.edu. FS and AH gratefully acknowledge financial support from the Swiss National Science Foundation, project grant no. 100018 _ 156787. 


\section{Introduction}

Which factors determine who loses and who wins in financial markets? Is it merely luck, or do traders need individual abilities, and if so, which? Recent research suggests that mental abilities correlate with the observed behavioral trading patterns. One strand of this literature focuses on quantitative or analytical abilities as the key determinant of successful asset trading because these skills are necessary to assess the fundamental value of an asset (e.g., Baghestanian, Lugovskyy, and Puzzello 2012; Corgnet et al. 2013; Noussair, Tucker, and Xu 2014). On the other hand, some papers suggest that the key determinant is a strong Theory of Mind, or mentalizing capability, which allows traders to "read the mind of the market" (Bruguier, Quartz, and Bossaerts 2010; De Martino et al. 2013).

In this paper, we propose that only an integrated model of both analytical and mentalizing abilities can adequately explain why certain traders are successful while others fail, despite the availability of the same information to all traders. We develop a unifying framework that explains the interaction between both mental capabilities and organizes the substantial heterogeneity of observed trading patterns in asset markets. Our model suggests that a one-dimensional measure of mental capabilities leads to an incomplete analysis of trading behavior, and to biased conclusions about what causes success in the asset market. We test the main predictions of our model in a standard experimental asset market, and find that the data support our theoretical conjectures.

\subsection{The Framework}

To make sense asset market data, researchers commonly assume heterogeneous behavior across traders (Boswijk, Hommes, and Manzan 2007). Explaining, beyond the purely descriptive level, the source of this heterogeneity is a central issue of behavioral research in 
economics and finance. ${ }^{1}$ We hypothesize that, even if information is perfectly symmetric among market participants, observed trading behavior is heterogeneous due to differences in mental capabilities. These varying mental dispositions lead to systematic differences in how humans evaluate the decision problem at hand. Specifically, we posit that the way traders think about investment decisions is the outcome of two fundamentally different mental capabilities. Analytical capability (A-Dimension) refers to a person's grasp of the quantitative aspects of a decision problem. This includes logical reasoning and mathematical or probabilistic calculations. Mentalizing capability (M-Dimension) is the ability to impute mental states to others and can be used to make predictions about their behavior (Premack and Woodruff 1978), that is, to understand others beliefs and intentions, which helps to predict their actions. ${ }^{2}$

Our framework conceptualizes how these two dimensions may determine behavior. We posit that each capability influences, in a distinctive way, how a situation is represented in the mind of the decision-maker. Our core assumption is that neither capability can be used as a substitute for the other. That is, having a strong analytical capability cannot make up for insufficient mentalizing, and vice-versa. A deficiency in one capability will then lead to a characteristic distortion of behavior. Therefore, heterogeneous behavior cannot be fully explained as a function of a one-dimensional measure of the two capabilities.

Our setting yields a classification of four different mental types, according to their ability in these two dimensions (Figure 1). "Technocratic" types (TE) have high analytical but low mentalizing ability. This type comprehends the logical and quantitative aspects of a situation, but cannot sufficiently account for the "psychological factor" in a strategic

1. As Hommes (2011) note: "An important challenge to a research program in behavioral economics and finance based on bounded rationality is to come up with a plausible and general theory of heterogeneous expectations."

2. Terms such as Theory of Mind, mentalizing, and cognitive empathy are often used interchangeably in the literature. The unifying aspect is the ability to put oneself in "the shoes of the others" (Frith and Singer 2008; Van Overwalle and Baetens 2009; Reniers et al. 2011). Analytical reasoning and mentalizing ability are stable and mostly independent traits among people (Reniers et al. 2011; Van Overwalle and Baetens 2009). 
Figure 1: The four basic mental types

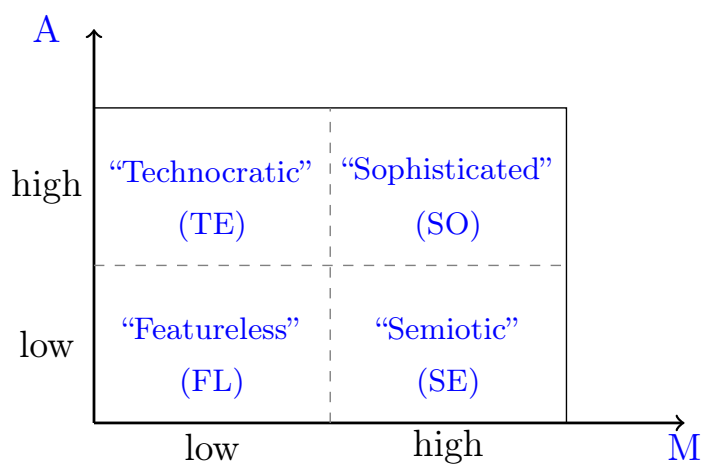

decision. For example, a technocratic type can correctly deduce the Nash equilibrium of a game, but has difficulties in making sense of deviations from equilibrium behavior. In contrast, "semiotic" types (SE) are keenly aware of others' behavioral patterns and can deduce intentionality from these patterns, but they lack a conceptual understanding of the decision situation. ${ }^{3}$ "Featureless" types (FL) have low levels of both analytical and mentalizing capabilities, while "Sophisticated" ( $\mathrm{SO}$ ) types are strong in both dimensions. They understand both the logical aspects of a decision situation and the possibility of intentional distortions by other agents.

We apply this framework to the asset market by suggesting that each person forms a mental model of the asset value on the basis of her individual mental capabilities. We posit that each of the two mental dimensions corresponds to one aspect of valuing an asset: to correctly understand the fundamental value of an asset, a trader needs analytical ability, and to correctly judge market sentiments she needs mentalizing ability. This is the basis for a testable model of mental capabilities and ensuing trading behavior.

The main predictions of our theory can be summarized as follows. The two-dimensional, non-convertible nature of mental capabilities generate distinguishable, characteristic trading patterns of the four mental types, which could be described as noise trading, funda-

3. We call this type semiotic because this type tries to read the behavioral "signs" of intentions in observables (such as past asset prices). 
mental trading, trend chasing, and bubble riding, respectively. Consequently, the four types vary in their success in the market. In particular, the most successful traders need both mental abilities, because only a combination of these skills allows a trader to appropriately understand both when prices depart from the fundamental and when they fall back. Therefore, we predict that SO will be the most profitable type.

Crucially, our theory predicts a non-monotonicity between capabilities and outcomes; being more skilled in one dimension does not necessarily imply higher profit. Analytical capability alone, however, does not generate substantial trading gains because a lack in mentalizing capability leads to a misinterpretation of price deviations from the fundamental. Therefore, TE should earn less than SO. Conversely, a strong mentalizing capability alone results in even more serious mistakes: semiotic traders will detect, and follow, an upward price trend but miss the optimal exit point since they do not sufficiently account for the fundamental. Accordingly, being skilled in only one dimension is not sufficient to develop a successful trading strategy, and may even be detrimental for the final outcome. Indeed, we show that when analytical capability is weak, not having mentalizing capabilities (i.e., being featureless) mitigates the expected trading losses. Therefore, we predict SE to incur the highest trading losses.

Another important and testable implication of our theory is that the "off-diagonal" types (TE and SE) should display the starkest contrast in trading patterns, because they lack the other type's capability. This prediction hinges crucially on our non-convertibility assumption of mental capabilities. If capabilities were substitutes, such that only the aggregate capability level matters rather than the type of capability, then behavior on the off-diagonal should be indistinguishable.

\subsection{The Experiment}

We conduct a laboratory experiment to validate our main hypotheses. Beyond the opportunity to measure participants' mental types, the laboratory offers the necessary control 
over the decision environment and the parameters. Most importantly, we can confine trading to a single asset, whose expected value we control. Moreover, we can make sure that all subjects have access to exactly the same information. This means that observable differences in behavior cannot be attributed to asymmetric information of the market participants but rather to their asymmetric processing.

Our experimental design consisted of two independent phases. In a first phase, we elicited participants' ability in both the analytical and the mentalizing dimension using separate, incentivized tasks, explained in detail in section 3.2. Participants' behavior in these tasks allows us to independently classify them into our four mental types. In a second phase, we observed participants' behavior in a standard experimental asset market game, which is widely known to yield a price bubble (Smith, Suchanek, and Williams 1988). They could trade shares of an asset for a total of 15 periods. We then used the collected data to test the various predictions of our model.

The empirical findings are consistent with our theoretical predictions. Analyzing subjects' trading patterns, we find that technocratic types largely trade on the fundamental, buying when the asset price is below or at the fundamental value, and selling when the price rises above it. These types make money from the dividend but miss out on the profits from speculating on the bubble. Semiotic types follow the rising asset price, with peak asset holdings slightly after the peak of the bubble. These types make the largest losses as they are unable to unload their shares profitably after the peak. The sophisticates anticipate both the rising and the bursting of the bubble. These types make the most money by having the best market timing. Finally, featureless types show no pronounced trading pattern.

\subsection{Related literature}

Within the large literature on the determinants of traders' behavior in (experimental) asset markets, we only review those that examine the role of analytical and mentalizing 
abilities, as these are most relevant for our approach. Analytical capability seems to have an effect on individual trading behavior, profits, and bubble size. For example, participants scoring well in the cognitive reflection test (Frederick 2005) achieve higher profits in laboratory spot markets (Corgnet et al. 2013), and in spot markets with an added futures market (Noussair, Tucker, and Xu 2014); their trading style is less focused on momentum and more on fundamental value (Baghestanian, Lugovskyy, and Puzzello 2012). On the other hand, Bruguier, Quartz, and Bossaerts (2010) do not find that cognitive ability is related to the ability to correctly predict asset prices, and Janssen, Weitzel, and Füllbrunn (2015) find no correlation between CRT and behavior in their speculation task. Concerning aggregate outcomes, markets with traders exhibiting higher average analytical abilities produce lower price volatility (Breaban and Noussair 2015; Cueva and Rustichini 2015). ${ }^{4}$ These observations are in line with studies on actual stock market behavior. In general people with higher IQ are more likely to trade in stock markets, hold a more diversified portfolio, and achieve higher Sharpe ratios than people with lower IQ, even after controlling for socio-demographic covariates (Korniotis and Kumar 2010; Grinblatt, Keloharju, and Linnainmaa 2011; Luik and Steinhardt 2015).

Bruguier, Quartz, and Bossaerts (2010) are among the first to provide evidence that "theory of mind" (ToM) and the ability to forecast prices are correlated. In their experiment, a strong ToM allows an observer to successfully discern malicious from benevolent intent in price patterns. ${ }^{5}$ De Martino et al. (2013) find that a higher mentalizing ability correlates with the tendency to ride the bubble too far and to lose money. ${ }^{6}$

According to our framework, these studies tell only part of the story. We contend

4. A recent study suggests that bubbles (and high volatility) arise through the interaction between different analytical types (Hanaki et al. 2015).

5. In their experiment, they compare the brain activation of subjects in markets with and without insiders. Subjects are rewarded for accuracy in predictions (forecasting market prices), but do not participate themselves in the market.

6. Neuro-economic evidence suggests that activity in certain brain regions is correlated with the asset trading behavior shown by some of our mental types. In particular, De Martino et al. (2013) link activity in the dorsomedial and ventromedial prefrontal cortex with behavior we see in our "Semiotic" mental type; Smith et al. (2014) find that activity in the nucleus accumbens is related to "Semiotic"-type behavior and the anterior insular cortex is related to "Sophisticated" behavior. 
that only the interaction of both independent dimensions can explain the complex heterogeneous behaviors we observe in asset markets, even under symmetric information. To our knowledge, our paper provides the first theoretical and experimental documentation of two separate and unrelated mental abilities that interact to generate diverse mental types displaying distinctive behavioral patterns.

\section{Theory}

Our theoretical framework explains how individual mental capabilities influence the mental model of a decision problem. Our core argument is that the two different capabilities, analytical reasoning and mentalizing, affect the individual thinking in a distinct, nonconvertible way. Applied to the asset market, our model then identifies four different mental types, and predicts that these types exhibit distinguishable, characteristic trading patterns, resulting in different profits.

\subsection{Mental models, capabilities and distortions}

In every period $t$ each trader $i$ forms a mental model to determine her valuation $V^{i}(t)$ for the asset, conditional on a set of observables. Let these observables be the past prices $\{P(0), \ldots, P(t)\}$ and the expected dividend $F(t)$. We posit that these two observables affect the individual mental models in a heterogeneous way, depending one someone's analytical and mentalizing capabilities. To fix ideas, suppose that the ideal mental model of the asset's value $V(t)$ depends on the fundamental value $F(t)$ and the last observed price $P(t)$ according to the mapping ${ }^{7}$

$$
V(t)=\tilde{\varphi}(F(t), P(t))
$$

7. We include only the last observed price for reasons of simplicity and tractability. A longer history would not change the nature of our predictions, and we can empirically test for several price lags (which turn out not to be relevant). 
Our theoretical framework builds on the postulate that each individual calibrates her mental model around (1), but may deviate systematically from (1) according to her mental capabilities. ${ }^{8}$ The observables $F(t)$ and $P(t)$ convey information of a different nature to a trader. ${ }^{9}$ First, the fundamental value of the asset corresponds to the expected stream of dividends $F(t)$ in the context of our experimental asset market. Correctly accounting for this component in the valuation of the asset requires analytical thinking (such as calculating expectations), and therefore is related to someone's analytical capabilities. Second, the market price, $P(t)$, is a consequence of others' bids and asks for the asset, so that each trader can try to infer from the price how others value the asset. The price is therefore an indicator of the "market sentiment", and understanding the importance of this component requires mentalizing about others. That is, to learn about the intentions of others, a trader must interpret the price history "semiotically", because the market price is the only observable that reveals the actions of others. Let the actual mental model of trader $i$ be a function

$$
V^{i}(t)=\tilde{\varphi}\left(d_{1}^{i}, F(t), d_{2}^{i}, P(t)\right)
$$

where $d_{1}^{i}, d_{2}^{i} \in[0,1]$ are trader-specific distortion coefficients, and $\tilde{\varphi}(\cdot)$ is twice continuously differentiable. Coefficient $d_{1}^{i}$ depends on the dimension "analytical reasoning", and $d_{2}^{i}$ on the dimension "mentalizing" of $i$. These mental capacities are quantified by $c_{j}^{i} \in \mathbb{R}_{+}$, where $j=1(j=2)$ is the analytical (mentalizing) dimension, and $\left(c_{1}^{i}, c_{2}^{i}\right)$ is trader $i$ 's mental profile. Let $\bar{c}_{1}, \bar{c}_{2}$ quantify how much capacity in a dimension is required to match the ideal model in the corresponding component. ${ }^{10}$ Our core assumption is that

8. This ideal model is akin to a Laplacian demon, an omniscient observer who accurately predicts the future market price using (1). Note that an ideal model can possibly be fitted ex-post, e.g., by estimating a linearized version of (1) on past asset market data.

9. We assume symmetric information, i.e., that all traders see the same set of observables.

10. It does not matter whether there is any individual who actually reaches these thresholds because our theory will identify the relative biases among the traders in the sample. Conversely, if all traders had $c_{j}^{i} \geq \bar{c}_{j}$, then everybody would have the ideal understanding of component $j$. Hence our theory offers a differential prediction only if the decision situation is cognitively complex enough, i.e., each $\bar{c}_{j}$ 
the distortions $d_{j}^{i}$, caused by deficient mental capabilities, affect the mental model (2) in a non-convertible way.

Assumption 1 (Non-convertibility). For $j=1,2$ each distortion coefficient $d_{j}^{i}$ is determined by a function $d_{j}: \mathbb{R}_{+}^{2} \rightarrow[0,1], d_{j}^{i}=d_{j}\left(c_{j}^{i}, \bar{c}_{j}\right)$, where $d_{j}\left(\cdot, \bar{c}_{j}\right)$ is strictly increasing for $c_{j}<\bar{c}_{j}$ and $d\left(c_{j}, \bar{c}_{j}\right)=1$ whenever $c_{j} \geq \bar{c}_{j}$. The function $\tilde{\varphi}(\cdot)$ verifies

$$
\frac{\partial^{2} \tilde{\varphi}}{\partial d_{1} \partial P}=\frac{\partial^{2} \tilde{\varphi}}{\partial d_{2} \partial F}=\frac{\partial^{2} \tilde{\varphi}}{\partial d_{1} \partial d_{2}}=0
$$

The distortion function $d_{j}\left(c_{j}^{i}, \bar{c}_{j}\right)$ quantifies the gap between an agents capacity $c_{j}^{i}$ and the capacity threshold level $\bar{c}_{j} .{ }^{11}$ Hence $d_{j}^{i}=d_{j}\left(c_{j}^{i}, \bar{c}_{j}\right)<d_{j}^{i^{\prime}}=d_{j}\left(c_{j}^{i^{\prime}}, \bar{c}_{j}\right)$ iff $c_{j}^{i}<c_{j}^{i^{\prime}}$ and $c_{j}^{i}<$ $\bar{c}_{j}$. Moreover, any trader with a sufficiently strong mental profile $\left(c_{1}^{i}, c_{2}^{i}\right) \geq\left(\bar{c}_{1}^{i}, \bar{c}_{2}^{i}\right)$ obtains (1), hence we normalize $\tilde{\varphi}(F(t), P(t)) \equiv \tilde{\varphi}((1, F(t)),(1, P(t)))$. Expression (3) means that any ceteris paribus change of $P$ has an effect on $V^{i}(t)$ that is independent of $d_{1}^{i}$, while any change of $F$ has an effect on $V^{i}(t)$ that is independent of $d_{2}^{i}$. Moreover, a change in distortion, say, $d_{2}$ has an effect on $V^{i}(t)$ that is independent of $d_{1}$. Because the distortion in dimension $j$ is independent of capacity level $c_{-j}$, mental capabilities are orthogonal to each other: Incorporating $F$ into the valuation recruits only analytical reasoning and incorporating $P$ only involves mentalizing. Any spare capacity $c_{j}^{i}-\bar{c}_{j}>0$ cannot compensate for a deficient capacity $-j$. The assumption that distortions depend in a non-convertible way on mental capabilities will have crucial (and falsifiable) ramifications for the predicted trading behavior.

Condition (3) is equivalent to the function $\tilde{\varphi}$ being additively separable in $\left(d_{1}, F\right)$ and is so large that $c_{j}^{i}<\bar{c}_{j}$ for some individuals.

11. A simple example is given by $d_{j}=c_{j} / \bar{c}_{j}$ for any $c_{j} \leq \bar{c}_{j}$. 
$\left(d_{2}, P\right) \cdot{ }^{12}$ Consequently, we let

$$
V^{i}(t)=\tilde{\varphi}\left(\left(d_{1}^{i}, F(t)\right),\left(d_{2}^{i}, P(t)\right)\right)=\tilde{\varphi}_{1}\left(d_{1}^{i}, F(t)\right)+\tilde{\varphi}_{2}\left(d_{2}^{i}, P(t)\right)+\varepsilon_{i}
$$

where the residual term $\varepsilon_{i}$ could depend on $d_{j}^{i}$ or $P, F .{ }^{13}$ For the main theoretical predictions of our model, $\varepsilon_{i}$ plays no vital role. For what follows, we will treat it as a random error term. The functions $\tilde{\varphi}_{1}, \tilde{\varphi}_{2}$ in equation (4) embody how the distortions $d_{1}, d_{2}$ may affect indiviudal valuations. Specifically, if $\frac{\partial \tilde{\varphi}_{j}}{\partial d_{j}}>0$, there is undervaluation in a component $j \in\{1,2\}$, and if instead $\frac{\partial \tilde{\varphi}_{j}}{\partial d_{j}}<0$ there is overvaluation compared to the ideal model

$$
V(t)=\tilde{\varphi}_{1}(1, F(t))+\tilde{\varphi}_{2}(1, P(t))
$$

Relative biases Since the asset market is very complex, it is conceivable that no trader has a mental profile that matches the threshold $\left(\bar{c}_{1}, \bar{c}_{2}\right)$. It is therefore important to realize that individual predictions obtainable from (4) are of a relative nature, where the traders with the comparably strongest mental profiles in the sample serve as a benchmark, by representing the best "human approximation" to (5). Suppose that in a sample of $I$ people some individual has $0<\left(c_{1}^{S}, c_{2}^{S}\right) \leq\left(\bar{c}_{1}, \bar{c}_{2}\right)$, where $c_{j}^{S}=\max \left\{c_{j}^{1}, \ldots, c_{j}^{I}\right\}$. Call this individual a Sophisticate, and define $\varphi_{j}\left(r_{j}^{i}, \cdot\right) \equiv \tilde{\varphi}_{j}\left(r_{j}^{i} d_{j}\left(c_{j}^{S}\right), \cdot\right)$, where $r_{j}^{i}=d_{j}\left(c_{j}^{i}\right) / d_{j}\left(c_{j}^{S}\right) \in[0,1]$ is the relative distortion of trader $i$. Note that $r_{j}^{i}=1$ iff $c_{j}^{i}=c_{j}^{S}$. With $r_{j}^{i}=r_{j}\left(c_{j}^{i}, c_{j}^{S}\right)$, where $r_{j}\left(\cdot, c_{j}^{S}\right)$ is strictly increasing, (4) can be expressed as

$$
V^{i}(t)=\varphi_{1}\left(r_{1}\left(c_{1}^{i}\right), F(t)\right)+\varphi_{2}\left(r_{2}\left(c_{2}^{i}\right), P(t)\right)+\varepsilon_{i},
$$

12. Additive separability between fundamental and price is common in the financial literature. For example, if $\tilde{\varphi}_{1}(\cdot), \tilde{\varphi}_{2}(\cdot)$ are linear functions, the resulting model corresponds to the asset demand in the rational noise trader environment (e.g., Hellwig 1980; Kyle 1985, 1989). Other examples that include the idea of heterogeneous trader types are De Long et al. (1990), Boswijk, Hommes, and Manzan (2007), and Kaizoji et al. (2015).

13. For example, $\varepsilon_{i}=\varepsilon_{1}\left(d_{1}^{i}\right)+\varepsilon_{2}\left(d_{2}^{i}\right)+\varepsilon_{3}(F, P)$ is an admissible residual term. 
Note that if the nature of the bias is undervaluation (overvaluation), then $\frac{\partial \varphi_{j}}{\partial r_{j}}>0$ $\left(\frac{\partial \varphi_{j}}{\partial r_{j}}<0\right)$. A simple special case obtains if each (relative) bias and the corresponding observable are multiplicatively separable. With undervaluation (4') then becomes ${ }^{14}$

$$
V^{i}(t)=r_{1}\left(c_{1}^{i}\right) \varphi_{1}(F(t))+r_{2}\left(c_{2}^{i}\right) \varphi_{2}(P(t))+\varepsilon_{i}
$$

\subsection{Type-specific asset holdings}

A central consequence of the above assumptions is that the process of individual valuation formation, and the corresponding trading behavior and asset-holding patterns, cannot be fully explained by a one-dimensional measure of mental capabilities. To make this evident, consider the simple case of binary capabilities, $c_{j}^{i} \in\{0,1\}$. This yields four mental profiles or mental types: ${ }^{15}$ (0,0) FL (featureless), (0,1) SE (semiotic), (1,0) TE (technocratic), $(1,1) \mathrm{SO}$ (sophisticate). ${ }^{16}$ Assumption 1 implies the following relations among the type-specific relative distortions $r_{j}^{i}: 17$

$$
\begin{array}{llll}
r_{1}^{T E}=r_{1}^{S O} & r_{1}^{S E} \neq r_{1}^{S O} & r_{1}^{S E}=r_{1}^{F L} & r_{1}^{F L} \neq r_{1}^{T E} \\
r_{2}^{T E} \neq r_{2}^{S O} & r_{2}^{S O}=r_{2}^{S E} & r_{2}^{F L} \neq r_{2}^{S E} & r_{2}^{F L}=r_{2}^{T E}
\end{array}
$$

Note that with undervaluation (overvaluation) in component $F$ or $P$ the $\neq$ in (7) become $<(>)$. How the type-specific distortions $\left(r_{1}^{i}, r_{2}^{i}\right)$ affect the valuations $V^{i}$ is sensitive to the shape of the ideal model (5) (and also depends on $\bar{c}_{j}$, i.e. on the mental difficulty of assessing the situation), respectively to the Sophisticate's version of it. As an example, consider a situation where the asset price is determined entirely by its fundamental $F(t)$,

14. With overvaluation, an example is given by $V^{i}(t)=1 / r_{1}\left(c_{1}^{i}\right) \varphi_{1}(F(t))+1 / r_{2}\left(c_{2}^{i}\right) \varphi_{2}(P(t))+\varepsilon_{i}$.

15. This also corresponds to our empirical classification of mental types in the evaluation of the experimental data. Generally, we could replace $\{0,1\}$ by $\left\{c_{L}, c_{H}\right\}$, where $c_{L}<c_{H}$, and would obtain the same conclusions.

16. See figure 1 .

17. Hence evidence supporting a distinguishable empirical pattern for these four mental types necessarily rejects a one-dimensional approach, because a one-dimensional measure of mental capabilities cannot span the entire "box" of mental types. 
i.e. $P(t)=P(F(t))$, consistent with the efficient market hypothesis. Since the past asset price then does not deviate from $F(t)$ it follows that $\tilde{\varphi}_{2}(\cdot, P(t))=0$ in $(5)$. If the price has no additional effect on the valuation, then (ignoring $\varepsilon^{i}$ ) $V^{S O}=V^{T E}=\varphi_{1}(1, F(t)$ ) and $V^{S E}=V^{F L}=\varphi_{1}\left(r_{1}^{S E}, F(t)\right)$. That is, we have only two types, which are defined by their analytical capacity. Moreover, if additionally $c_{1}^{\theta} \geq \bar{c}_{1}$ already for $\theta=S E, F L$, that is, everybody's analytical capacity is high enough to understand the fundamental, then all types should form essentially the same mental model, and therefore display an indistinguishable trading pattern. In other words, our theory does not predict that the four mental types will always show a distinct behavior.

Because traders act according to their subjective valuation (4'), the number of shares held by a trader type reflects her valuation (relative to the others). We argue that if both $F(t)$ and $P(t)$ are determinants of the ideal model, then indeed different trading patterns can emerge. In particular, differences in mental capabilities, leading to different relative biases, can cause a different response to a change in the observables. Let $\alpha_{1}^{i}=\alpha_{1}\left(r_{1}^{i}, F\right) \equiv$ $\frac{\partial \varphi\left(r_{1}^{i}, F\right)}{\partial F}$ and, analogously, $\alpha_{2}^{i}=\alpha_{2}\left(r_{2}^{i}, P\right) \equiv \frac{\partial \varphi\left(r_{2}^{i}, P\right)}{\partial P}$ denote trader $i$ 's stimulus response to the corresponding observable. If valuations are determined by (6), then the two different mental profiles $\left(c_{1}^{i}, c_{2}^{i}\right),\left(c_{1}^{i^{\prime}}, c_{2}^{i^{\prime}}\right)$ with $c_{j}^{i}<c_{j}^{i^{\prime}}$ yield an everywhere differential stimulus response in an observable iff $\varphi_{j}(\cdot)$ is strictly monotonic. More specifically, this means that if $\varphi_{1}^{\prime}(\cdot), \varphi_{2}^{\prime}(\cdot)>0$, then according to $(7)$ the valuation of $\mathrm{SE}$, and hence her asset holdings, should respond less sensitive to a change in $F$, and more sensitive to a change in $P$ compared to TE. Intuitively, this captures that SE underestimates the importance of the fundamental for the price determination, while TE underestimates the importance of the last observed price.

More generally, the model predicts a differences in the stimulus responses between different mental types if $\varphi_{j}(\cdot)$ is strictly super- or submodular. ${ }^{18}$ We say that $\varphi_{j}(\cdot)$ is strictly modular if $\varphi_{j}(\cdot)$ is either strictly super- or submodular. Consider a linearized

18. Strict super(sub)modularity is equivalent to increasing (decreasing) differences, and means that, e.g., $\alpha_{1}(\cdot, F)$ is strictly increasing (decreasing). 
version

$$
V^{i}(t)=\alpha_{1}^{i} F(t)+\alpha_{2}^{i} P(t)+\operatorname{rest}(t)
$$

of (4'). If $\varphi_{j}$ is strictly modular, and $c_{j}^{i}<c_{j}^{S O} \leq \bar{c}_{j}$, then (4") yields different response coefficients $\alpha_{j}^{i} \neq \alpha_{j}^{i^{\prime}}$ whenever $c_{j}^{i}<c_{j}^{i^{\prime}} \leq \bar{c}_{j}$. Undervaluation (overvaluation) means that if $c_{j}^{i}<c_{j}^{i^{\prime}}$, then trader $i$ responds less (more) to the corresponding observable than a trader $i^{\prime}$ with a stronger capacity in dimension $j$. Hence, in terms of stimulus responses, undervaluation (overvaluation) means $\left|\alpha_{j}\left(r_{j}^{i}, x\right)\right|<(>)\left|\alpha_{j}\left(r_{j}^{i^{\prime}}, x\right)\right|$, where $\operatorname{sign}\left(\alpha_{j}\left(r_{j}^{i}, x\right)\right)=\operatorname{sign}\left(\alpha_{j}\left(r_{j}^{i^{\prime}}, x\right)\right) .{ }^{19}$ Note that strict modularity is consistent with the most serious case of miscalibration, where even an inversion of the response coefficients occurs between types, i.e. where $\operatorname{sign}\left(\alpha_{j}\left(r_{j}^{i}, \cdot\right)\right) \neq \operatorname{sign}\left(\alpha_{j}\left(r_{j}^{i^{\prime}}, \cdot\right)\right){ }^{20}$

How does possessing one or both mental capabilities affect the resulting stimulus response coefficients? Given a sufficiently complex asset market $\left(0<\bar{c}_{j}, j=1,2\right)$, one central prediction of our model is that if $\varphi_{j}(\cdot)$ is modular, then the off-diagonal types differ in their response to the respective observable:

(H1) (Antipodal types) If for $j \in\{1,2\} \varphi_{j}(\cdot)$ is strictly supermodular (submodular) then $\alpha_{1}^{T E}>(<) \alpha_{1}^{S E}$ or $\alpha_{2}^{S E}>(<) \alpha_{2}^{T E}$, respectively.

Non-convertibility is crucial for this hypothesis, because if deficiencies could compensate each other, e.g., because only average capacity $\left(c_{1}+c_{2}\right) / 2$ matters, then TE and SE would have the same distortion coefficients. Further, we should be able to confirm the following hypothesis

(H2) (Samecapabilities) $\alpha_{1}^{T E}=\alpha_{1}^{S O}$ and $\alpha_{2}^{S E}=\alpha_{2}^{S O}$.

This hypothesis is even more fundamental than $\mathrm{H}(1)$, as it follows directly from nonconvertibility (assumption 1), and does not depend on the modularity of $\varphi_{j}(\cdot)$. That is, if capabilities were to affect valuations in a convertible way, then $d_{2}^{S O} \neq d_{2}^{S E}$ and thus

19. If $\varphi_{j}\left(r_{j}, \cdot\right)$ is increasing, the notion of under- and overvaluation is tied to the modularity of $\varphi_{j}(\cdot)$. Particularly, there then is undervaluation (overvaluation) in observable $j$ if $\varphi_{j}(\cdot)$ is strictly supermodular (submodular).

20. In particular, the case $\alpha_{2}\left(r_{j}^{i}, P\right)<0<\alpha_{2}\left(r_{j}^{i^{\prime}}, P\right)$ is consistent with supermodularity of $\varphi_{2}(\cdot)$. 
$\alpha_{2, \mathrm{SE}} \neq \alpha_{2, \mathrm{SO}}$ is possible.

\subsection{Implications for trading behavior}

We now derive our main hypothesis about individual trading behavior from the above notion of mental modeling. Specifically, we shall obtain a dynamic conjecture about the asset holding patterns and an aggregate conjecture about the distribution of trading gains.

Asset-trading hypothesis We begin by establishing that if an asset market with a single asset and a falling fundamental features a price bubble,${ }^{21}$ then our model predicts the four types to display a distinguishable and characteristic trading pattern over the various market phases. In fact, this is why we chose this type of asset market for our experiment.

In the following derivation we consider general valuations $V^{\theta}$ given by (4'), where $\theta \in$ $\{F L, S E, S O, T E\}$ and the type-specific random variables $\varepsilon_{\theta}$ are distributed according to a joint density $f\left(\varepsilon_{F L}, \ldots, \varepsilon_{S O}\right)>0 .{ }^{22}$ We focus on the case, where both functions $\varphi_{j}(\cdot, \cdot)$ are strictly supermodular, because this captures intuitive types of (relative) biases, such as undervaluation or inversion, as discussed above. Moreover, this turns out to be most relevant empirically.

Let $\operatorname{Pr}(\theta \mid F, P) \equiv \operatorname{Pr}\left(V^{\theta}=\max \left\{V^{F L}, V^{S E}, V^{T E}, V^{S O}\right\}\right)$ be the probability that type $\theta$ holds the highest valuation among all four mental types, given observables $F, P$. The following elementary proposition summarizes how these type-specific probabilities shift as the observables $F, P$ change.

Proposition 1. If $\varphi_{j}(\cdot, \cdot), j=1,2$, is strictly supermodular, then $\operatorname{Pr}(\theta \mid F, P)$ depends on the observables F, $P$ as stated in Table 1

21. It is well-known that in such experimental asset markets bubbles occur in the Lab.

22. For example, we could have $\varepsilon_{\theta}=\bar{\varepsilon}_{\theta}+\varepsilon$, where $\bar{\varepsilon}_{\theta}$ is a (possibly type-specific) constant and $\varepsilon$ is an iid random variable. However, note that we do not require the $\varepsilon_{\theta}$ to be independent. 


\begin{tabular}{|l|c|c|c|c|}
\hline $\operatorname{Pr}(\theta \mid F, P)$ & $\theta=F L$ & $\theta=S E$ & $\theta=T E$ & $\theta=S O$ \\
\hline$d F<0, d P>0$ & $?$ & + & - & $?$ \\
\hline$d F<0, d P<0$ & + & $?$ & $?$ & - \\
\hline
\end{tabular}

Table 1: Type-specific valuation patterns

A proof of Proposition 1 is in section 6.1 of the appendix. The "?" in Table 1 means that the effects of $(F, P)$ are countervailing for the respective type, and therefore cannot be signed unambiguously. To obtain some intuition for Proposition 1, suppose that the fundamental falls while the price rises $(d F<0, d P>0)$. Then $V^{S E}$ increases unambiguously because SE fails to sufficiently account for the falling fundamental but responds to the increasing price, while $V^{T E}$ unambiguously decreases because this type does not adequately adjust for the increasing price. SO counterbalances a steady or increasing price against a falling fundamental, while FL fails to sufficiently account for either of the two components. That is, these two types exhibit ambiguous tendencies, so that neither type is likely to have the highest valuation, given that $d F<0, d P>0$.

Again, the predictions summarized in Table 1 rest on the non-convertibility assumption. In particular, if only an aggregate and hence one-dimensional capacity measure is relevant, then TE and SE should show an indistinguishable valuation pattern. Similarly, if only the capacity in one dimension is relevant at least two types should be indistinguishable. ${ }^{23}$

Note that, by supermodularity, table 1 extends to the cases where either $d F>0, d P<$ 0 or $d F, d P>0$ by inverting the respective signs. Hence Proposition 1 would predict that if both fundamental and price are increasing (such as in a Bull market), valuations of SO tend to increase most as only this type adequately accounts for both observables. The general prediction derived from Table 1 thus is that the off-diagonal types TE and

23. For example, if only analytical reasoning mattered and $\varphi_{2}(\cdot)=k$, a constant, then $V^{T E}$ and $V^{S O}$ should behave identically. 
SE should display a mutually reversed valuation pattern if $F$ and $P$ move in opposite directions, while the on-diagonal types FL and SO should display a mutually reversed valuation pattern if $F$ and $P$ move in the same direction. It follows that we can expect to observe a differential pattern between all four types if $P(t)$ and $F(t)$ evolve differently. ${ }^{24}$

Proposition 1 has direct implications for the type-specific asset holding patterns over the phases of a price bubble, because traders try to buy or sell shares according to their subjective valuation (4'), and therefore the number of shares $A^{\theta}$ held by type $\theta$ increases in $\operatorname{Pr}(\theta)$. Given that $F(t)$ decreases in $t$ and $P(t)$ follows a hump-shape pattern, i.e. $P(t)$ increases for periods $\{1, \ldots, \hat{t}\}$ and decreases strictly for periods $\{\hat{t}+1, \ldots, T\}$, our model predicts the following type-specific patterns: ${ }^{25}$

\section{(H3) (Asset-trading hypothesis)}

\begin{tabular}{|c|c|c|c|c|}
\hline & $A^{F L}$ & $A^{S E}$ & $A^{T E}$ & $A^{S O}$ \\
\hline$t \leq \hat{t}$ & $?$ & + & - & $?$ \\
\hline$t>\hat{t}$ & + & $?$ & $?$ & - \\
\hline
\end{tabular}

Table 2: Asset holding hypothesis

Table 2 predicts that the various types should accumulate or decumulate assets during the two market phases according to a differential pattern. The "?" in table 2 mean that the effects of $(F, P)$ are countervailing for the respective type, and therefore we expect to observe a flat or a non-monotone pattern of $A^{\theta}$ in the corresponding region of $t$.

The intuitive explanation for the type-specific trading patterns as predicted in (H3) is as follows. According to $\left(4^{\prime}\right)$ it depends on the mental profile if the asset is under- or overvalued by type $\theta$ relative to SO. Let $H(\theta) \equiv \operatorname{Pr}\left(V^{\theta} \leq V^{\mathrm{SO}}\right)$ be a type's probability

24. Note that the reason why $P(t)$ may deviate from the fundamental is the presence of semiotic types, since these types tend to underestimate the fundamental and hence "over-perceive" the value of the asset. Thus, besides successfully decomposing the heterogeneity in the individual trading patterns, our model could also provide an explanation for why a bubble forms in the first place. Pursuing this reasoning further, however, is beyond the scope of the present paper.

25 . These predictions would remain valid under the slightly weaker assumption that $P(t)$ is nondecreasing in periods $\leq \hat{t}$. 
of undervaluing the asset relative to $\mathrm{SO}$, where

$$
H(\theta)=\operatorname{Pr}\left(\varepsilon_{\theta}-\varepsilon_{\mathrm{SO}} \leq \varphi_{1}\left(r_{1}^{S O}, F\right)-\varphi_{1}\left(r_{1}^{\theta}, F\right)+\varphi_{2}\left(r_{2}^{S O}, P\right)-\varphi_{2}\left(r_{2}^{\theta}, P\right)\right)
$$

If $\theta=\mathrm{TE}$, then $H(T E)=\operatorname{Pr}\left(\varepsilon_{T E}-\varepsilon_{\mathrm{SO}} \leq \varphi_{2}\left(r_{2}^{S O}, P\right)-\varphi_{2}\left(r_{2}^{T E}, P\right)\right)$ is increasing in $P$, implying that TE tends to undervalue the asset compared to SO (and SE) at high observed prices. This occurs because, while both types assign the same weight to the analytical component, TE underestimates the importance of the mentalizing component, which determines the distortion in $V^{T E}$ relative to $V^{S O}$. Turning to SE we see that $H(S E)$ is an increasing function of $\varphi_{1}(\cdot)$. Because $F(t)$ decreases over time, the chances of SE to overvalue the asset relative to $\mathrm{SO}$ (and hence TE) also increase as long as prices rise. Therefore, SE should acquire shares throughout the build-up of the Bubble while TE does the opposite. Moreover, if $d F<0, d P>0$, such that a bubble builds up, it is more likely that SE rather than FL acquires expensive shares, because FL does not account as much for high prices as SE.

Trading-gains hypothesis The difference in the asset holding patterns occurring in a bubble market translate into differential overall trading gains among the four mental types. Our definition of the Sophisticate as the person with the (relatively) best ability to calibrate her mind to the asset market implies that Sophisticates should achieve the highest trading gains. Given that $P(t)$ is hump-shaped, $V^{S O}>V^{T E}$ becomes more likely around the max of $P(t)$, implying that $\mathrm{SO}$ holds on to or even acquires shares, while TE rather seeks to (prematurely) sell them (also see Table 2). This earlier exiting of TE relative to SO prevents TE from incurring trading losses by selling out early, but also means that TE tends to forgo some of the trading gains that SO realizes. We therefore expect TE to make non-negative trading gains, but lower gains than SO. Next, the chances of $\mathrm{SE}$ to overvalue the asset relative to $\mathrm{SO}$ also increase over time, because $F(t)$ decreases over time and $H(S E)$ is an increasing function of $\varphi_{1}(\cdot)$. Hence SE buys or holds on shares at high prices, which she cannot sell at all or only at substantial 
losses after the bubble peaks. Thus we expect SE to incur trading losses. One might be inclined to conjecture that FL should incur the highest trading losses because this type lacks both capabilities. However, from Table 2 we see that if $d F<0, d P>0$, such that a bubble builds up, it is more likely that SE rather than FL acquires expensive shares. Thus, the two biases of FL have a tendency to offset rather than reinforce each other. On the one hand, FL might accumulate some shares which she later cannot sell profitably because she fails to account for the fundamental, hence FL tends towards lower trading gains than TE. On the other hand FL incurs smaller losses than SE because FL tends to value the asset lower than SE at high prices because she fails to account for $P(t)$. We summarize these predictions under the following empirically testable hypothesis:

(H4) (Trading-gains hypothesis) The trading gains $G_{\theta}, \theta \in\{F L, S E, S O, T E\}$, are distributed over the four mental types as follows.

1. $G_{S O}>G_{T E}, G_{F L}, G_{S E}$

2. $G_{S E}<G_{T E}, G_{F L}, G_{S E}$

3. $G_{T E}>G_{F L}$

Hypothesis H4 summarizes a central insight of our model: Mental capabilities have a non-monotone effect on expected type-specific trading gains. The highest gains and highest losses both occur to types with high mentalizing capacity. Given high mentalizing abilities, analytical skill then is decisive for whether someone wins or loses. Intuitively, this follows because the ability to correctly anticipate a systematic (upward) deviation of the price from the fundamental value requires a strong ability to mentalize that others may follow such a tendency, which neither FL nor TE possess. This lack of skill implies that FL and TE have much more difficulty to follow a possibly profitable price trend, but also tends to protect them from incurring trading losses due to a misjudgment of the price evolution. Such misjudgment is exactly why SE makes the highest losses. As SE does not sufficiently account for the fundamental value, SE essentially lacks the skill 
to appropriately understand that the price increasingly departs from the fundamental. Therefore this type still purchases assets around the bubble peak, which later either cannot be sold at all or only at high trading losses.

\section{Experimental Design}

The laboratory has several advantages for testing our hypotheses. First, it allows us to measure independently each individual's mental capacities through different, incentivized tasks. Then, we can observe the same individual's behavior in an experimental asset market. The experimental asset market gives us control over the market environment. In particular, we can restrict trading to a single asset. Importantly, we can control the fundamental value of this asset, which is determined by a simple stochastic dividend process. Importantly, this also prevents any form of privileged trading through asymmetric information about the fundamental value, as all participants are informed about the dividend-generating process. We can exogenously endow participants with cash and shares of the asset. We can impose that every participant has the same objective, maximizing cash at the end of the final period of the asset market. We can exogenously choose the market structure, so that - in our case - participants can simultaneously place buy and sell orders over multiple periods. Finally, since experimental asset markets like ours reliably produce bubbles, we can observe individual behavior in bubbly markets as a function of mental capabilities.

\subsection{Procedure}

We conducted 8 experimental sessions with 32 participants each at the laboratory of the economics department at the University of Zurich. ${ }^{26}$ All experimental sessions, consisting of two phases, began with participants being seated in front of their computer

26. We used hroot (Bock, Baetge, and Nicklisch 2014) for recruitment and ztree (Fischbacher 2007) for programming the experiment. 
terminals, and then receiving general information about the procedures. ${ }^{27}$ Then, participants started with Phase 1 of the experiment: In phase 1, each participant completed a series of tasks that are designed to obtain performance-based measures of the analytical and mentalizing capacities. All tasks were incentivized, yielding CHF0.30 per correct answer/round won. Except for the Game of Nim, participants did not receive feedback about their performance before the end of the experiment. Phase 1 (capability measurement) of each session took about 45 minutes. Following this phase, participants had a short break (about 10 minutes) to recuperate. Phase 2 consisted of an experimental financial market where participants could trade shares of an asset against cash. Each session had two markets with 16 participants each. We provided participants with detailed paper instructions, which were read aloud in front of all participants. ${ }^{28}$ Participants then had to answer comprehension questions. ${ }^{29}$ The asset market did not start before all participants had answered all questions correctly. Finally, we implemented two payoff-irrelevant practice periods to make participants more familiar with the computer interface. After the practice rounds, the 15 actual trading periods ensued. The income from phase 2 consisted of the amount in their cash account at the end of the asset market. Shares of the asset became worthless at that point. Phase 2 took on average a little over 90 minutes. After Phase 2, we administered the exit questionnaire and paid out participants in cash as they left the laboratory. ${ }^{30}$ One entire session lasted about 2.5 hours. The earnings for the entire session were the sum of the earnings for each task in phase 1, the cash holdings at the end of period 15 in the asset market plus a show-up fee of CHF 10. On average subjects earned around CHF 70 (minimum CHF 23, maximum $\mathrm{CHF} 121)^{31}$

27. See online material (Hefti, Heinke, and Schneider 2016).

28. See online material (Hefti, Heinke, and Schneider 2016).

29. For details see online material (Hefti, Heinke, and Schneider 2016).

30. The questionnaire is available from the authors on request.

31. For details see online material. 


\subsection{Phase 1: Measuring Mental Capabilities}

In phase 1, instructions for each of the tasks were presented on participants' computer screens, before the task started. Each task was designed to capture a specific aspect of either the analytical or the mentalizing ability dimension. ${ }^{32}$ For each of the two capacity dimensions, the performance measure is the the percentage of correct answers or rounds won. Thus the maximum possible score in each dimension is equivalent to 100, implying that all tasks have been completed without mistakes.

For the analytical dimension, we chose three frequently used experimental tasks that reflect general intelligence (Raven's Progressive Matrices), mathematical and logical skill (SAT-style word problems, Bruguier, Quartz, and Bossaerts 2010), and strategic reasoning (Game of Nim, McKinney Jr and Van Huyck 2006). ${ }^{33}$

Mentalizing is the ability to make accurate inferences about the mental states of others. As stated above, this requires at least two abilities, (1) to recognize and identify others' intentions ("perspective taking") and (2) develop a correct working model about the resulting behavior ("online simulation") (Reniers et al. 2011). Incentivized tasks assessing both abilities are more difficult to find than for the analytical dimension. ${ }^{34}$ We followed Bruguier, Quartz, and Bossaerts (2010) and operationalized this ability dimension with two separate tests. In the first one, participants had to infer other people's mental states (reading the mind in the eye test), in the other they had to infer intentions from others' actions (Heider-Simmel Test). ${ }^{35}$

32. During this phase, we additionally elicited risk attitude, using a standard Holt-Laury-type price list. The lottery choice was fixed to a 50 : 50 chance of winning either CHF 20 or nothing, and the certain payment moved upward from CHF 0 in increments of CHF 1.

33. For a more detailed description of each task see online material (Hefti, Heinke, and Schneider 2016).

34. Psychologists traditionally use self-reported measures, such as questionnaires (e.g., Reniers et al. 2011).

35. For a more detailed description of each task see online material (Hefti, Heinke, and Schneider 2016). Both performance in the Reading the mind in the eye test and the Heider-Simmel Task correlate positively with the ability to forecast price changes when insiders are present in the experimental asset market (Bruguier, Quartz, and Bossaerts 2010). This indicates that participants scoring high in these tasks are able to detect when price movements are due to intentional actions by insiders. 
To obtain a good approximation of the underlying distributions of the two measures, we use data from 640 participants. ${ }^{36}$ Figure 2 displays the joint distribution of the two dimensions. The red line shows the linear fit. The corresponding correlation coefficient

Figure 2: Distribution of $\mathrm{A}$ and $\mathrm{M}$ performance measures

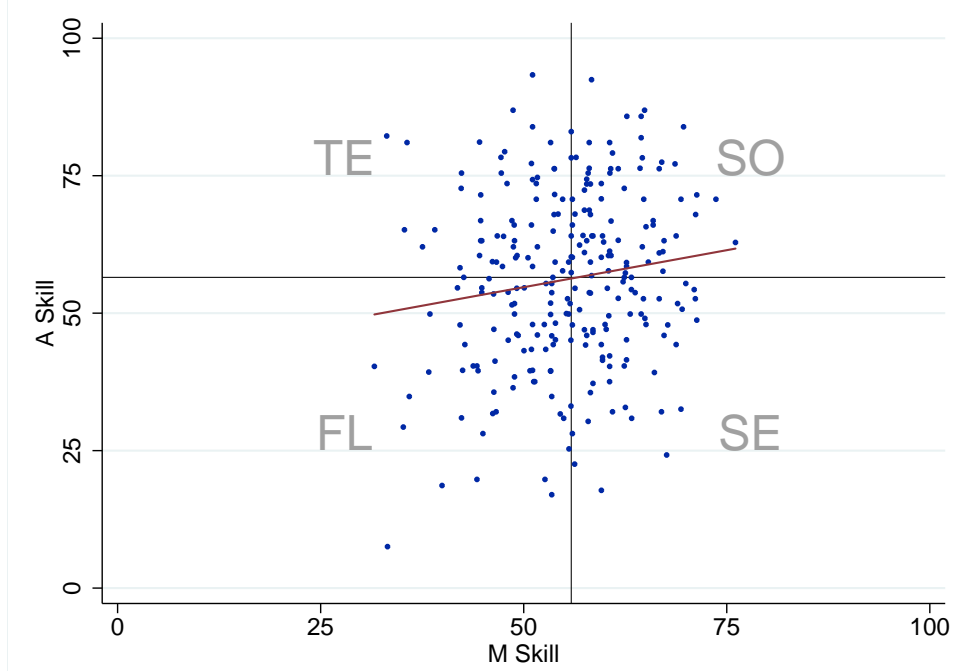

Each dot represents a participant. The horizontal axis shows the participant's performance in the M dimension, the vertical axis the performance in the A dimension. The dot cloud suggests little relation between the two measures, as highlighted of the red line of best linear fit. The black lines indicate the median for each measure.

$\rho=0.099$ suggests a weak correlation between the two measures $(p=0.012, N=640)$. The black horizontal and vertical lines indicate the median for each dimension. We use the resulting four quadrants to classify our participants into our four mental types, Featureless (FL), Semiotic (SE), Technocratic (TE), and Sophisticated (SO).Table 3 lists the basic summary statistics of the total group and by mental type. The participants in each skill category are similar with respect to age, with a mean age around 23 years in all four categories. We cannot reject the null hypothesis of no contingency (Pearson $\chi^{2}$ test, $\left.p=0.207, N=640\right)$. The four groups are less balanced with respect to gender

36. The data come from 40 experimental asset markets including two other treatment conditions that are part of another paper. In these conditions, we exogenously create markets that consist of more extreme types. 
Table 3: Summary Statistics by Mental Type

\begin{tabular}{lrrrr}
\hline $\begin{array}{l}\text { Mental Participants } \\
\text { Type }\end{array}$ & Women (\%) & Age (years) & Av. risky choices \\
\hline $\begin{array}{l}\text { Featureless } \\
\text { (FL) }\end{array}$ & 166 & 59.6 & 23.5 & 11.6 \\
$\begin{array}{l}\text { Semiotic } \\
(\mathrm{SE})\end{array}$ & 155 & 66.5 & 23.4 & 11.1 \\
$\begin{array}{l}\text { Technocratic } \\
(\mathrm{TE})\end{array}$ & 155 & 29.7 & 22.8 & 12.1 \\
$\begin{array}{l}\text { Sophisticated } \\
(\mathrm{SO})\end{array}$ & 164 & 43.3 & 23.0 & 12.3 \\
\hline Total & 640 & 49.8 & 23.1 & 11.8 \\
\hline
\end{tabular}

Age and risk attitude are similar across mental types. Men tend to score higher in the A dimension, resulting in a gender imbalance across skill types.

( $\chi^{2}$ test, $p<0.01, N=640$ ) because women and men tend to perform differently on the A dimension. ${ }^{37}$ We also elicited participants' risk preferences using a Holt-Laury-type choice task (Holt and Laury 2002) between a lottery that yields either CHF20 or CHF0 with equal probability and a certain amount. The last column of Table 3 shows the average number of times that a participant chose the lottery over the certain amount. The differences across mental types are small and we cannot reject the null hypothesis of no contingency ( $\chi^{2}$ test, $p=0.214, N=640$ ).

\subsection{Phase 2: Experimental Asset Market}

We used a call market version of the Smith-Suchanek-Williams asset market (Smith, Suchanek, and Williams 1988). ${ }^{38}$ In each market, 16 participants were endowed with

37. On average, women score 54 points out of 100 , and men score about 63 points (t-test, $p<0.01$, $N=640)$. On the other hand, women tend to perform slightly better on the $\mathrm{M}$ scale, where women score on average 57 points, and men 56 points (t-test, $p=0.05, N=640$ ).

38. We implemented a slightly modified version of the call market from the GIMS program for asset market experiments in ztree (Palan 2015). 
cash and shares of an asset. ${ }^{39}$ The asset market was divided into 15 periods. Each period had a trading phase, where participants could trade shares against cash, followed by a dividend phase, where the asset payed a randomly drawn dividend. ${ }^{40}$

In each period participants could trade shares by submitting one sell order and one buy order. ${ }^{41}$ A buy order consisted of the maximum price that a participant is willing to pay for a share, and the number of shares that the participant is willing to buy if the market price is equal or lower than this maximum. Conversely, a sell order consisted of the minimum price at which a participant is willing to sell a share, and the number of shares that the participant is willing to sell if the price is equal or higher than this minimum. ${ }^{42}$ The computer automatically collected all buy and sell orders and calculated the market-clearing equilibrium price.

For our experiment, the call market offers multiple advantages over a double auction. First, we assume in our model that market participants are atomistic and have no possibility to influence the market price. The call market procedure, together with the comparatively large number of market participants (16), made it harder to make manipulative orders (Baghestanian et al. 2014). Second, the call market is the more conservative choice to test our hypotheses. ${ }^{43}$ Finally, compared to the double auction

\footnotetext{
39. A market had 40 assets in circulation and each participant was randomly endowed with one of four possible portfolios, with an average of 2.5 shares and 1820 Rappen in cash. 100 Rappen $=1$ Swiss Franc ( 1 Swiss Franc $\approx$ USD 0.98 at the time of the experiment).

40. Shares of the asset have no intrinsic value beyond the dividend stream. The dividend is drawn from the set $d \in\{0,8,28,60\}$, each equal probability. We generated a random dividend stream at the beginning of the study and used the same stream in each of the sessions to keep the inflow of cash constant across all markets.

41. The online material (Hefti, Heinke, and Schneider 2016) shows the trading screen.

42. Participants can leave their buy/sell order blank, in which case they will not buy/sell shares in this period. The computer does not accept orders that violate a participant's budget constraints, that is, buying on credit and short selling are not allowed.

43. Because call markets give fewer opportunities for making offers and trading shares, they exhibit fewer price mirages (over-reactions to uninformative offers and trades), are in general closer to the rational expectation equilibrium, and have less trading price volatility than double auctions. On the other hand, the removal of within-period trading dynamics in call markets reduces the opportunities both for speculative trading (Baghestanian et al. 2014) and for learning about others' trading strategies. Thus, a call market reduces the amount of offers and the size of the asset bubble compared to a double auction, which should limit the downside risk of trend followers and the upside scope for speculation by bubble riders. All effects on the M-dimension we find in a call-market environment should be at least as
} 
the call-market is faster, which helped to keep the total session duration manageable.

\section{Results}

\subsection{Trading Gains and Total Income}

A central prediction of our theory is that the four mental types earn different trading gains. Consequently, we start the empirical analysis by testing the trading gains hypothesis $\mathrm{H} 4{ }^{44}$

Result 1 (Trading outcomes). SO realizes the highest trading gain (and overall income), SE the highest trading losses (and lowest overall income). By pairwise comparison, all mental types earn different total income and trading gains, as predicted by hypothesis $\mathrm{H}_{4}$, except that we cannot reject that TE and FL earn the same trading gains and overall income. Focusing on one capability measure would mask important heterogeneity among traders.

Figure 3a depicts the average trading gains for the four mental types by the end of the experiment. ${ }^{45}$ The figure shows that the trading gains are substantially different for the four mental types. In particular, the order of the trading gains $\left(G_{S O}>G_{T E}>\right.$ $\left.G_{F L}>G_{S E}\right)$ in the figure is the one we predicted in hypothesis H4. While SE loses 390 Rappen on average, SO gains 403 Rappen over the course of the asset market. FL (45 Rappen loss) TE (93 Rappen gain) lie in between.

The goal for the subjects in the experimental asset market is to maximize the cash at the end of the final period. Subjects can earn cash either through dividends on shares pronounced in a double auction.

44. In section 3.2 we already found that risk attitudes are largely uncorrelated with mental capabilities. In the same spirit, we find that all our results remain valid when controlling for risk attitudes.

45. Cash at the end of a period $t$ comes from three different sources: initial cash, cumulative dividends from periods 1 to $t$, and cumulative trading gains from sales and purchases in periods 1 to $t$. Therefore, the cumulative trading gain in a period is simply the residual if we subtract initial cash and cumulative dividend income from current cash. 
Figure 3: Trading gains across mental capability types.

(a) Difference in Trading Gains

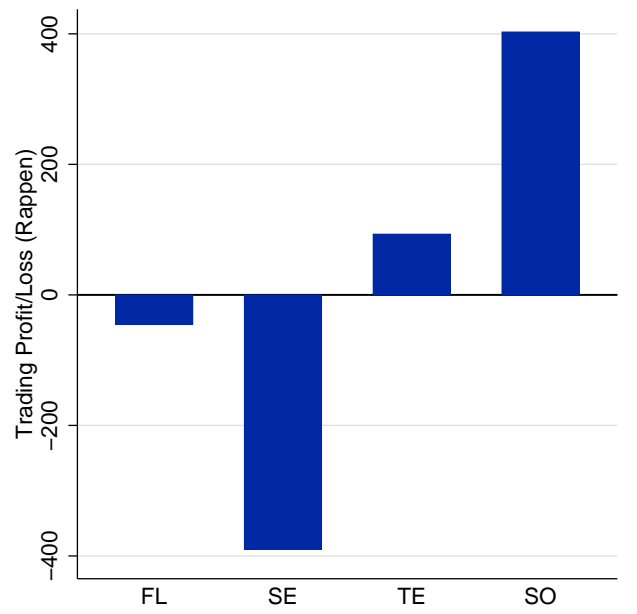

(b) Difference in Income

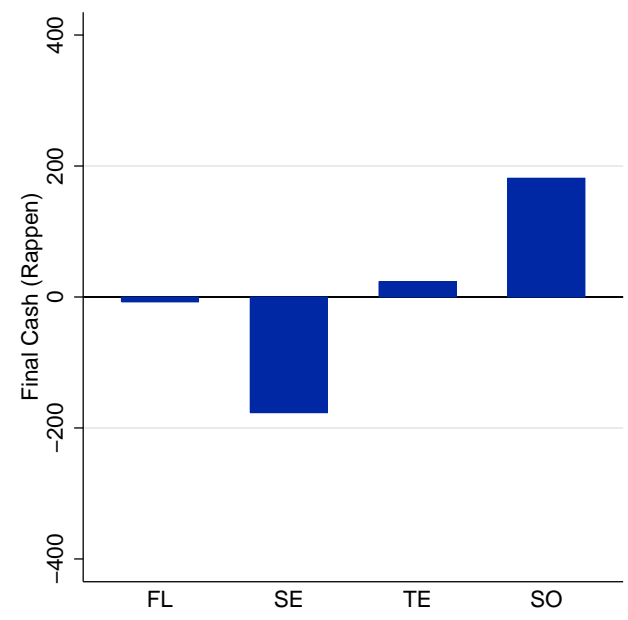

The vertical axis shows the outcome variables trading income and cash at the end of the asset market. The right panel shows the deviation from average cash holdings in period 15, by type. SE earns the least amount, 177 Rappen below average, and SO the highest amount, 181 Rappen above average. The two other types lie in between, with FL slightly below average and TE a bit above average.

they hold, or through trading gains, by buying shares at a low price and selling them at a high price. Figure $3 \mathrm{~b}$ shows the incomes of the four types from the asset markets. We see the same order as in Figure $3 a^{46}$ In particular, Sophisticates earn the most of all four types, 358 Rappen more than SEs, who have the worst outcome of all mental types. ${ }^{47}$ Moreover, comparing figures Figure 3a and 3b reveals that the difference in total income is driven by the difference in trading gains, and not by the dividend income. ${ }^{48}$

A regression analysis confirms the impression from figure 3. The results of OLS regressions of the two outcome measures, cash and trading gains, on type dummies (FL is the omitted category) are presented in Table 4. The regression framework allows us to additionally control for risk aversion (number of lottery choices in the multiple price

\footnotetext{
46. A subject's income in the asset market is equal to the amount of cash at the end of the final period.

47. We also find suggestive evidence that performance is most consistent among the Sophisticates and least consistent among Semiotic types, who have a 30 percent higher standard deviation in final cash (SO: 658 Rappen, TE: 682 Rappen, FL: 721, SE: 853 Rappen).

48. Dividend income tends to mitigate the difference between SOs and SEs, because SEs hold more shares on average than SOs.
} 
list), and to correct standard errors for clustering at the session level. The Sophisticated type outperforms all three other types in terms of final cash (first column). Conversely, the Semiotic type performs worse than all other types. Risk attitudes do not change this result. Table 4 provides statistical evidence in favor of hypothesis H4. ${ }^{49}$ The only problematic comparison is between FL and TE, where we cannot reject the possibility these two types realize the same trading gains and total income. But this does not mean that FL and TE are empirically indistinguishable types. Below we show that the similar profits of FL and TE are the results of two different behavioral patterns.

The results for trading gains (second column) are qualitatively the same, only with greater magnitudes and smaller $p$-values. Risk aversion does not significantly affect any of the three outcomes. Furthermore, we obtain the same qualitative results when excluding those ambiguous subjects who score close to the medians of the two mental dimensions.

Figure 3 and Table 4 show that, consistent with our theory, focusing on only one capability measure would produce a seriously biased picture by masking the interaction of the capabilities. ${ }^{50}$ In particular, we would wrongly conclude that high analytical capability implies higher trading gains (and total income), if we ignored mentalizing capability. ${ }^{51}$ In reality, this result is entirely driven by the large earnings of SO; the earnings of TE are not significantly different from zero. This means mentalizing ability is crucial for the success of SO. Similarly, if we ignored analytical reasoning, we would wrongly conclude that mentalizing is entirely irrelevant in the asset market: As Figure 3 shows, this is because the gains and losses of SO and SE (TE and FL) tend to offset each other. ${ }^{52}$ Hence we would miss that mentalizing ability is responsible for both the highest

\footnotetext{
49. Because hypothesis H4 is of a one-sided nature, we could divide the standard errors by 2 , showing that all pairwise hypotheses are as stated in $\mathrm{H} 4$ at least at the $5 \%$ level, except the comparison between TE and FL.

50. See appendix 6.2 for the split along one dimension.

51. A simple regression, not reported here, of the A-capability, where either our effective measure of the A-capability or a capability dummy is used as left-hand variable, shows that trading gains and total income are significantly increasing in the A-dimension.

52. A simple regression, not reported here, of the M-capability reveals no significant effect of mentalizing on trading gains and total income.
} 
gains and the largest losses.

\subsection{Trading Patterns}

Our theory predicts that the four mental types display distinct, characteristic trading patterns over the various market phases. Specifically, our model predicts individual asset holdings to show a type-specific stimulus response to a change of the observables "fundamental" and "last price" (hypothesis H1-H2). As a consequence of the corresponding stimulus-response equation (4'), the asset holdings of the four types should obey specific portfolio dynamics over the course of the experiment as predicted in hypothesis H3. We now test the hypothesis about the type-specific stimulus-response coefficients and the portfolio dynamics hypothesis, starting with the latter.

\subsubsection{Portfolio dynamics}

Result 2 (Portfolio dynamics). We find empirical trading patterns that are strongly consistent with our model (hypothesis H3). While FL trades little, SE strongly increases its position while the bubble builds up, and holds the highest amount of shares even beyond the peak of the bubble. TE divests before the price peak, while SO is the only type who profitably divests after the bubble bursts.

Figure 4 depicts average asset holdings over time for the four mental types, while the right figure shows how the trading gains develop over time. The figure shows a substantial difference in how the asset holdings of the four mental types evolve over time, once both observables become available. ${ }^{53}$

Of all types, FL has the flattest asset holding pattern, with a slight upwards tendency in pre-price-peak phase, which is broadly consistent with our observation from Section 2.3 that the two relative biases of FL tend to offset each other. SE is the only type who

53. In the first period there is no past asset price. At the end of the first period, we cannot reject the hypothesis that all four types hold the same number of shares (Kruskal-Wallis, $p=0.727, N=256$ ). 
Figure 4: Asset holdings and cumulative trading gains over time, by type.
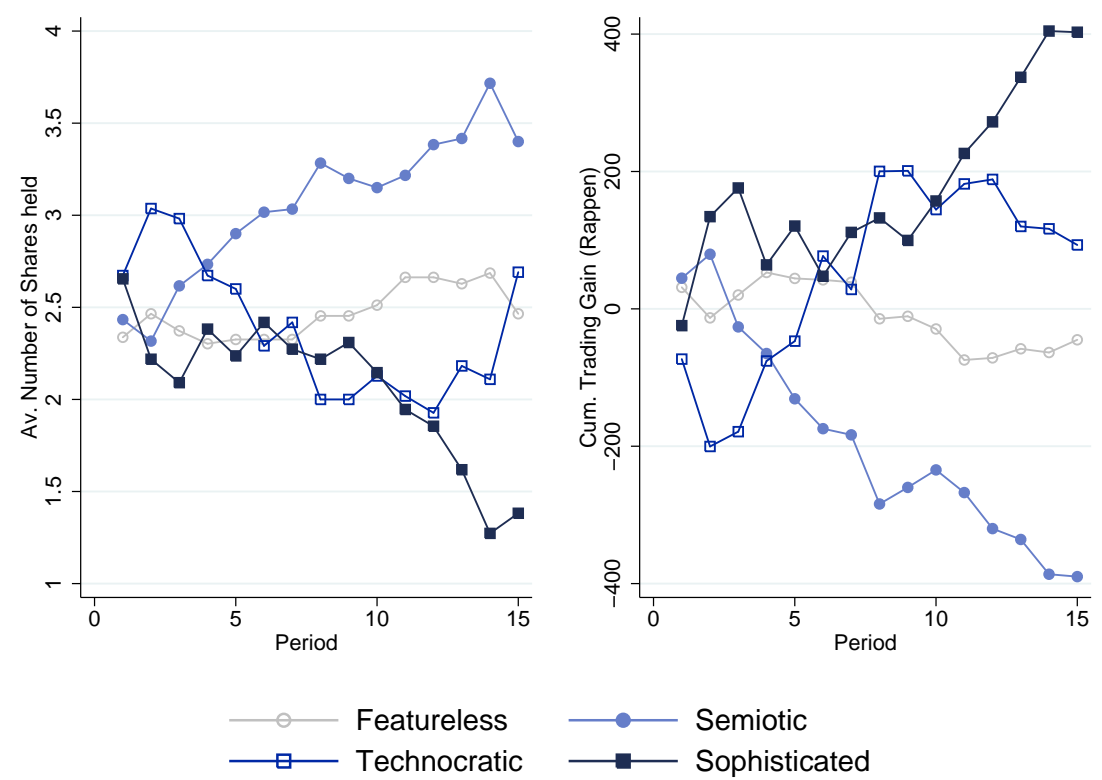

The left graph shows the different portfolio strategies of the four types, by plotting the asset holdings for each type over time. The right graph shows the resulting trading gains. All four types show distinct portfolio dynamics.

accumulates assets during the entire market. Both TE and SO tend to reduce their holdings, albeit in different market phases.

To formally test hypothesis H3, we analyze subjects' behavior separately for the periods before the market price reaches its peak ("pre-price-peak") and after the peak (post-price-peak). On average, prices reach their peak between period 6 and 7 . Therefore, we fit two linear regressions, on for the pre-price-peak market phase and one for the postprice-peak market phase (Table 5).

The results support that the portfolio dynamics of the for mental types are consistent with the theoretical predictions in hypothesis H3. First, in the pre-price-peak phase SE accumulates while TE divests over time. Both FL and SO do not seem to systematically vary their asset holdings during this market phase. Second, in the post-price-peak phase 
FL acquires shares while SO sells shares over time. In contrast to the pre-phase, TE and SE now do not seem to vary their asset holdings as time progresses, and we cannot reject the hypothesis that SE and TE behave similarly during this market phase.

The regressions in Table 5 together with Figure 4 provide additional insight into the source of the different final trading gains. We see that the accumulative tendency of FL during the post phase tends to burden this type with some trading losses, because FL acquires assets while the price is still falling. Further, SE makes most of the trading losses due to the assets bought in the pre phase, which cannot be sold in the post phase. Finally, SO achieves the highest trading gains especially because this type is the most successful seller in the post bubble phase, where he outperforms TE.

\subsubsection{Stimulus response coefficients}

In the previous section we tested our predictions about the portfolio dynamics of the different types. These predictions were derived from the model's type-specific stimulusresponse equations (4'). In this section, we test whether the stimulus response coefficients are consistent with our theory (hypothesis H1-H2).

Result 3 (Stimulus response coefficients). TE and SE display different stimulus response coefficients to both observables, as predicted by hypothesis H1. Moreover, the coefficients have opposite signs, consistent with inversion as the strongest form of miscalibration as identified by our theory. SE and SO have statistically similar response coefficients to last price, while TE and SO have statistically similar response coefficients to the fundamental, as predicted by hypothesis H2.

Table 6 shows random effects regressions of asset holdings as a function of the fundamental and the last price, allowing for differences across mental types. ${ }^{54}$ Figure 5 illustrates the estimated stimulus response coefficients, showing the heterogeneity across

54. We present the results with and without controlling for risk aversion. As before, risk aversion has no influence on the estimation results. 
Figure 5: Marginal effects of fundamental and last price on asset holdings

(a) Marginal effects of fundamental

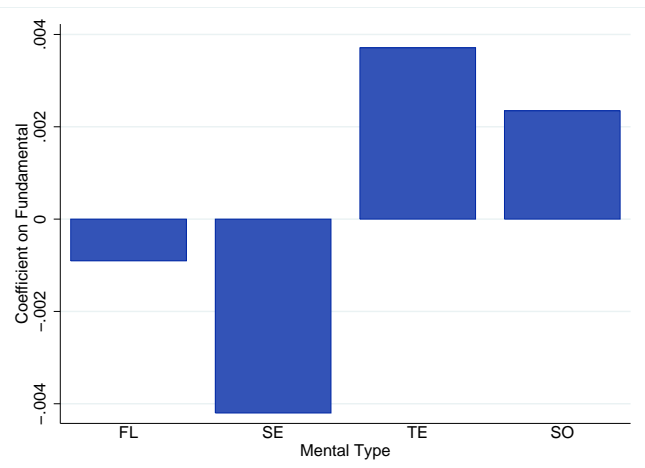

(b) Marginal effects of previous price

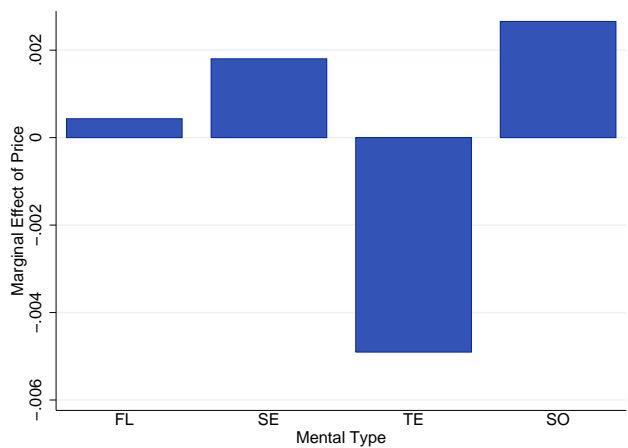

The graphs show marginal effects of fundamental value (left) and previous market price (right) on shares held from regression M1 in table 6 by mental type. SO reacts positively to both the fundamental and the last price; $\mathrm{SE}$ only reacts positively to last price, TE only positively to fundamental. Both SE and TE react inversely to their "deficient" dimension.

the four mental types. The relations among the estimated coefficients are as predicted by hypothesis $\mathrm{H} 1$ and $\mathrm{H} 2$.

The off-diagonal types TE and SE have opposite signs in their response coefficients to both observables. As predicted in hypothesis H1, TE's response coefficient of the fundamental (last price) is significantly positive (negative), while SE responds significantly negative (positive) to the fundamental (last price). The difference in the coefficients between these two types is highly significant (see Table 6). The negative coefficients are consistent with inversion, the strongest form of miscalibration. This result highlights that the same set of observables can lead to a diametrically opposed perception and decisions if mental capabilities are different.

Figure 5 further suggests that SO and TE have similar response coefficients of the fundamental, and that SO and SE have similar response coefficients of the last price. The regression analysis in table 6 indeed shows that we cannot reject the hypothesis that these coefficients are similar, consistent with hypothesis $\mathrm{H} 2$. 


\subsection{Market Timing}

Exit timing is crucial in a bubble market, both for trading gains and losses. Since Sophisticates reap the highest gains and Semiotic types incur the highest losses, we should expect that Sophisticates exhibit the best exit timing and Semiotic types the worst.

Result 4 (Market Timing). SO has the best market timing, showing the largest net sale of shares among all types right at the bubble peak. TE sells too early, and SE sells too late.

Figure 6: Net aggregate sales and purchases of shares by mental type. Periods are aligned so that period 0 is the bubble peak of each market.

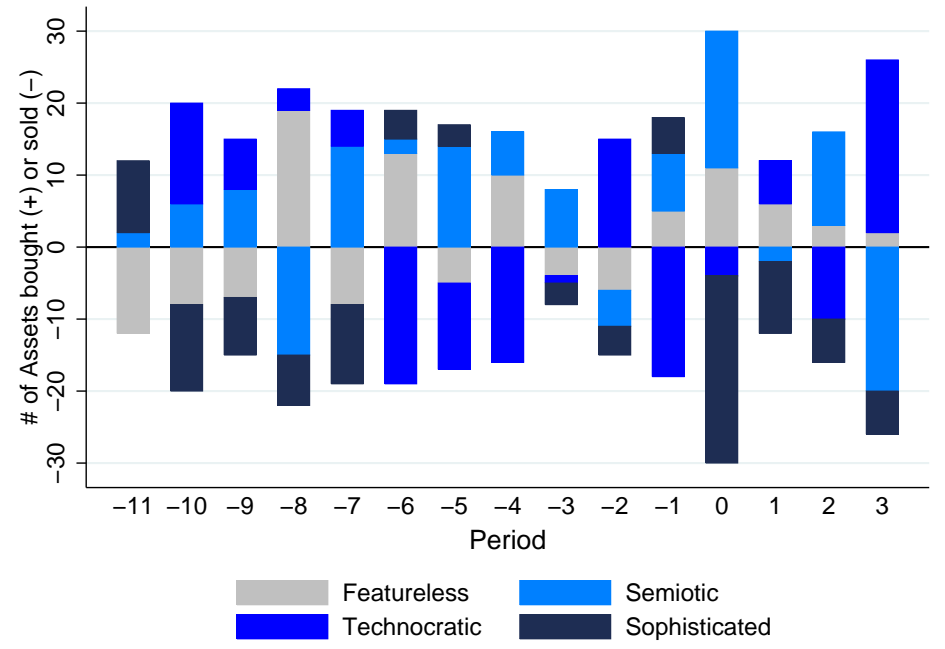

The graph shows the order of the exit timing: TE exits first, several periods before the bubble peak; SO exits right at the bubble peak; SE misses the exit and divests only after prices have collapsed.

Figure 6 shows average net sales and purchases over time across mental types. We adjust the periods so that the period of the bubble peak in each market is denoted as period $0 .{ }^{55}$ Before the bubble peak, FL's do not show a systematic pattern in sales and

55. The bubble peak is the period where the over-pricing of the asset relative to the fundamental is maximal. The average bubble peak occurs between period 11 and 12 in the experiment. 
purchases, but are net buyers at and after the bubble peak. SE's tends to buy in almost every period before the bubble peak. TE buys early (when the price is still close to the fundamental) but also sells early, about 6 to 4 periods before the bubble peak. The largest turnover of all periods occurs right at the bubble peak, where most of the shares are sold by SO types to SE types. That is, SO's have the best market timing of all mental types. TE has a worse timing, exiting the market to early, and SE has the worst timing, being a net buyer in almost all periods before and at the bubble peak, and a net seller only three periods after the peak, when the market price has fallen close to or below the fundamental value.

To test if SO has the best market timing, we investigate portfolio changes before an increase in the bubble component (market price minus fundamental value) and before a decrease in the bubble component. We regress the portfolio changes on an indicator of whether the bubble component will increase in the next period, and on interactions between this indicator and the type dummies (output omitted). We find that only Sophisticates correctly adjust their portfolio in anticipation of a change in the bubble component $(p=0.006)$. This adjustment is also significantly different from the adjustment of the other three types (SE: $p=0.002$, TE: $p=0.019$, FL: $p=0.064$ ). The other three types do not significantly anticipate the change. SE's even seem to get it the wrong way, divesting before an increase in the bubble component and investing before a decrease $(p=0.110)$.

\section{Conclusion}

Anecdotal evidence suggests that a purely "fundamentalist" approach to asset trading, without an understanding of the psychology of the market, may not yield maximum profits. For example, both Julian Robertson of Tiger funds and John Templeton correctly identified that dot-com stocks were overpriced in the late 1990s. Robertson shorted them 
too early because he did not anticipate the size and duration of the bubble; but Templeton understood the market "sentiment" better and shorted in 2000, right before the bubble burst (Zuckerman 2000). ${ }^{56}$

We argue that traders like Robertson and Templeton do not fit in a one-dimensional spectrum of trader types. Instead, we develop a simple framework that conceptualizes how two independent mental dimensions, analytical reasoning and mentalizing, determine an agent's mental model of the decision she faces. This framework yields a tractable model of how mental capabilities translate to asset trading behavior. Our core conjecture is that each capability determines one aspect of asset valuation. The ability to evaluate the fundamental value of an asset depends on analytical capability while the ability evaluate market sentiment depends on the mentalizing capability. As a consequence of the two-dimensional, non-convertible nature of mental capabilities, we predict four mental types. These types represent the four possible combinations of analytical and mentalizing capability (low-low, high-low, low-high, high-high). Each type has unique, distinguishable trading patterns, which lead to different profits. This two-dimensional view differs from the existing literature, which has focused on either one or the other dimension. Our approach is also fundamentally different from the literature about how heterogeneous information affects the trading in asset markets. We posit that even if traders with the same information will evaluate this information very differently if they have different mental types.

We examine our main theoretical predictions in a laboratory asset market. This approach allows us to control the environment tightly and to measure the traders' mental types. We find that both mental capabilities determine individual trading behavior and profits. Consistent with our theory, analytical capability alone is not enough to maximize

56. The investor George Soros pointed out the importance of sentiment: sometimes market prices "do not merely reflect the so-called fundamentals; they themselves become one of the fundamentals which shape the evolution of prices" (Soros 2003). These moments of "irrational exuberance," when prices detach themselves from the fundamental, are "the psychological basis of a speculative bubble," according to Robert Shiller (Shiller 2015). 
trading gains without a strong accompanying mentalizing capability. We call traders with high analytical but low mentalizing capability "Technocrats." This type can avoid major losses because they correctly identify the fundamental value of the asset and exit early. On the other hand, their inability to correctly analyze the intentions of others prevents them from exploiting the price bubble.

To anticipate such a bubble, a trader also needs an understanding of the "animal spirits" in a market. ${ }^{57}$ She needs to realize when the price deviates from the fundamental and when the bubble peaks. Consistent with our prediction, only Sophisticated types, who possess both capabilities, can ride a price bubble and time their exit correctly. As a consequence, they also make the highest profits of all four types. The Semiotic type has only mentalizing capability. This is outright detrimental as this type can only identify the upward price trend but fails to realize the departure from the fundamental. As predicted by our theory, this type therefore incurs the largest trading losses.

Because our framework explains observed heterogeneity in trading behavior and success, institutional traders may be able to select traders according to their mental capabilities to increase trading gains. Concerning public policy, interventions targeting Semiotic types, who are most prone to follow a price bubble, may help to reduce the size of such bubbles.

On the theoretical side, we think that our approach can offer a new view on recent accounts of off-equilibrium behavior (such as asset market bubbles). This behavior is outside the scope of traditional game theory. In the last two decades, research has incorporated behavioral aspects into the standard framework. Some approaches introduce the possibility for random mistakes in people's choices (McKelvey and Palfrey 1995); others assume that people's responses are optimal, but based on flawed beliefs (Stahl and Wilson 1995; Camerer, Ho, and Chong 2004). Since we formulate (and test) a specific

57. Keynes, who coined the term animal spirits in this context, was himself a successful speculator. He acknowledged that "there is the instability due to the characteristic of human nature that a large proportion of our positive activities depend on spontaneous optimism rather than mathematical expectations" (Keynes 1936). 
cognitive foundation (differential mental capabilities) for diverging behavior, our contribution provides a new take on both types of mistakes. In particular, biased beliefs could be the result of deficient mentalizing capability, while failure to best-respond could be based on lacking analytical capability.

As a framework for off-equilibrium behavior, we believe that our two-dimensional capabilities approach has potential beyond financial markets and may be adapted to explain behavioral puzzles in other domains. For example, a couple of recent studies examine the role of "strategic sophistication", which we see as an combination of our two mental dimensions. ${ }^{58}$ It would therefore be interesting to investigate strategic games, such as the Beauty Contest, using our classification of mental types.

58. Bosch-Rosa, Meissner, and Bosch-Domènech (2015) find that markets with strategic sophisticates generate smaller than average bubbles. Similarly, Levine, Bernard, and Nagel (2015) find that strategic sophisticates make higher profits in experimental asset markets. Finally, strategic sophisticates showed higher activation in a brain region associated with Theory of Mind (Coricelli and Nagel 2009). 
Table 4: Regression analysis of asset market outcomes across mental types

\begin{tabular}{lcc}
\hline & Cash & Trading Gain \\
\hline Semiotic & $-169.426^{*}$ & $-349.796^{* * *}$ \\
Technocratic & $(101.520)$ & $(118.288)$ \\
& 30.592 & 136.603 \\
Sophisticated & $(68.473)$ & $(166.107)$ \\
& $188.896^{* *}$ & $447.873^{* * *}$ \\
\# Lottery choices & $(83.541)$ & $(167.741)$ \\
& -0.249 & -5.656 \\
Constant & $(9.609)$ & $(15.838)$ \\
& $2840.468^{* * *}$ & 22.535 \\
adj. $R^{2}$ & $(107.861)$ & $(206.381)$ \\
N & 0.011 & 0.037 \\
Clusters & 256 & 256 \\
\hline
\end{tabular}

Type comparisons:

$\begin{array}{crr}\mathrm{SE}=\mathrm{TE} & \chi^{2}=3.40 & \chi^{2}=6.40 \\ & p=0.065 & p=0.011 \\ \mathrm{SO}=\mathrm{TE} & \chi^{2}=2.73 & \chi^{2}=2.96 \\ & p=0.099 & p=0.085 \\ \mathrm{SO}=\mathrm{SE} & \chi^{2}=14.12 & \chi^{2}=23.45 \\ & p<0.001 & p<0.001\end{array}$

OLS regressions, bootstrapped standard errors in parentheses, 1000 repetitions, adjusted for clustering at the session level. Unit of observation: participant.

Significance levels: ${ }^{*} \mathrm{p}<0.1,{ }^{* *} \mathrm{p}<0.05,{ }^{* * *} \mathrm{p}<0.01$.

Dependent variables: Cash and trading gains for entire asset market, in Rappen.

Independent variables: Constant: Featureless type. "Semiotic," "Technocratic," "Sophisticated": dummies for mental type; \# Lottery choices: number of times a participant chose the lottery over the certain amount in the Holt-Laury task. 
Table 5: Regression analysis of portfolio dynamics over time, across types

\begin{tabular}{lcc}
\hline & pre-price-peak & post-price-peak \\
\hline Period & 0.017 & $0.054^{* * *}$ \\
& $(0.060)$ & $(0.017)$ \\
$\mathrm{TE}$ & $1.259^{* *}$ & 0.300 \\
& $(0.494)$ & $(0.636)$ \\
$\mathrm{SE}$ & -0.505 & $1.379^{* *}$ \\
& $(0.323)$ & $(0.574)$ \\
$\mathrm{SO}$ & -0.171 & 1.165 \\
& $(0.603)$ & $(0.896)$ \\
$\mathrm{TE} \times$ Period & $-0.225^{*}$ & -0.050 \\
& $(0.116)$ & $(0.053)$ \\
$\mathrm{SE} \times$ Period & $0.158^{* *}$ & -0.042 \\
$\mathrm{SO} \times$ Period & $(0.075)$ & $(0.042)$ \\
& -0.024 & $-0.161^{* * *}$ \\
Constant & $(0.115)$ & $(0.055)$ \\
& $2.382^{* * *}$ & $1.883^{* * *}$ \\
\hline overall $R^{2}$ & $(0.238)$ & $(0.300)$ \\
$\mathrm{N}$ & 0.020 & 0.036 \\
Clusters & 1312 & 2272 \\
\hline
\end{tabular}

Assets change over time?

\begin{tabular}{ccc} 
Period $+\mathrm{SE} \times$ Period $=0$ & $\chi^{2}=25.33$ & $\chi^{2}=0.15$ \\
& $p<0.001$ & $p=0.703$ \\
Period $+\mathrm{TE} \times$ Period $=0$ & $\chi^{2}=6.29$ & $\chi^{2}=0.00$ \\
& $p=0.012$ & $p=0.945$ \\
Period $+\mathrm{SO} \times$ Period $=0$ & $\chi^{2}=0.01$ & $\chi^{2}=5.04$ \\
& $p=0.913$ & $p=0.025$ \\
\hline
\end{tabular}

Type comparisons:

$\begin{array}{lrr}\mathrm{SE} \times \text { Period }=\mathrm{TE} \times \text { Period } & \chi^{2}=15.39 & \chi^{2}=0.01 \\ & p<0.001 & p=0.915 \\ \mathrm{SO} \times \text { Period }=\mathrm{TE} \times \text { Period } & \chi^{2}=2.83 & \chi^{2}=1.45 \\ & p=0.093 & p=0.228 \\ \mathrm{SO} \times \text { Period }=\mathrm{SE} \times \text { Period } & \chi^{2}=6.41 & \chi^{2}=4.02 \\ & p=0.011 & p=0.045\end{array}$

Random effects panel regressions, standard errors adjusted for clustering at the session level. Unit of observation: participant-period.

Significance levels: ${ }^{*} \mathrm{p}<0.1,{ }^{* *} \mathrm{p}<0.05,{ }^{* * *} \mathrm{p}<0.01$.

Dependent variable: Shares held at end of period.

Independent variables: Constant: FL. SE, SO, TE: dummies for mental type. 
Table 6: Stimulus response regression, across types

\begin{tabular}{|c|c|c|}
\hline & M1 & M2 \\
\hline $\mathrm{SE}$ & $\begin{array}{l}0.793^{*} \\
(0.421)\end{array}$ & $\begin{array}{l}0.794^{*} \\
(0.423)\end{array}$ \\
\hline $\mathrm{TE}$ & $\begin{array}{r}0.949 \\
(1.092)\end{array}$ & $\begin{array}{r}0.949 \\
(1.093)\end{array}$ \\
\hline $\mathrm{SO}$ & $\begin{array}{l}-1.797^{* *} \\
(0.727)\end{array}$ & $\begin{array}{l}-1.796^{* *} \\
(0.728)\end{array}$ \\
\hline Fundamental & $\begin{array}{l}-0.001 \\
(0.001)\end{array}$ & $\begin{array}{r}-0.001 \\
(0.001)\end{array}$ \\
\hline $\mathrm{SE} \times$ Fundamental & $\begin{array}{l}-0.003^{* *} \\
(0.001)\end{array}$ & $\begin{array}{l}-0.003^{* *} \\
(0.001)\end{array}$ \\
\hline TE $\times$ Fundamental & $\begin{array}{l}0.005^{* *} \\
(0.002)\end{array}$ & $\begin{array}{l}0.005^{* *} \\
(0.002)\end{array}$ \\
\hline $\mathrm{SO} \times$ Fundamental & $\begin{array}{l}0.003^{*} \\
(0.002)\end{array}$ & $\begin{array}{l}0.003^{*} \\
(0.002)\end{array}$ \\
\hline Market Price $_{t-1}$ & $\begin{array}{r}0.000 \\
(0.001)\end{array}$ & $\begin{array}{r}0.000 \\
(0.001)\end{array}$ \\
\hline $\mathrm{SE} \times$ Price $_{t-1}$ & $\begin{array}{r}0.001 \\
(0.001)\end{array}$ & $\begin{array}{r}0.001 \\
(0.001)\end{array}$ \\
\hline $\mathrm{TE} \times$ Price $_{t-1}$ & $\begin{array}{l}-0.005^{*} \\
(0.003)\end{array}$ & $\begin{array}{l}-0.005^{*} \\
(0.003)\end{array}$ \\
\hline $\mathrm{SO} \times$ Price $_{t-1}$ & $\begin{array}{r}0.002 \\
(0.003)\end{array}$ & $\begin{array}{r}0.002 \\
(0.003)\end{array}$ \\
\hline \# Lottery choices & & $\begin{array}{r}0.001 \\
(0.023)\end{array}$ \\
\hline Constant & $\begin{array}{l}2.465^{* * *} \\
(0.290)\end{array}$ & $\begin{array}{l}2.457^{* * *} \\
(0.466)\end{array}$ \\
\hline $\begin{array}{l}\text { overall } R^{2} \\
\mathrm{~N} \\
\text { Clusters }\end{array}$ & $\begin{array}{r}0.029 \\
3440 \\
16\end{array}$ & $\begin{array}{r}0.029 \\
3440 \\
16\end{array}$ \\
\hline $\begin{array}{l}\text { Type comparisons Fundamental: } \\
\text { SE } \times \text { Fun. }=\text { TE } \times \text { Fun. }\end{array}$ & $\chi^{2}=17.31$ & $\chi^{2}=17.29$ \\
\hline $\mathrm{SO} \times$ Fun. $=\mathrm{TE} \times$ Fun & $\begin{array}{l}p<0.001 \\
\chi^{2}=0.31 \\
p=0.578\end{array}$ & $\begin{array}{l}p<0.001 \\
\chi^{2}=0.31 \\
p=0.578\end{array}$ \\
\hline $\mathrm{SO} \times$ Fun. $=\mathrm{SE} \times$ Fun & $\begin{aligned} \chi^{2} & =10.32 \\
p & =0.001\end{aligned}$ & $\begin{aligned} \chi^{2} & =10.32 \\
p & =0.001\end{aligned}$ \\
\hline 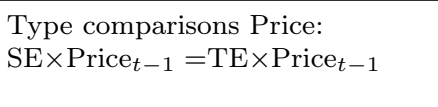 & $\begin{array}{l}\chi^{2}=5.10 \\
p=0.024\end{array}$ & $\begin{array}{l}\chi^{2}=5.10 \\
p=0.024\end{array}$ \\
\hline $\mathrm{SO} \times$ Price $_{t-1}=\mathrm{TE} \times$ Price $_{t-1}$ & $\begin{array}{l}\chi^{2}=3.24 \\
p=0.072\end{array}$ & $\begin{array}{l}\chi^{2}=3.24 \\
p=0.072\end{array}$ \\
\hline $\mathrm{SO} \times$ Price $_{t-1}=\mathrm{SE} \times$ Price $_{t-1}$ & $\begin{array}{l}\chi^{2}=0.13 \\
p=0.715\end{array}$ & $\begin{array}{l}\chi^{2}=0.13 \\
p=0.716\end{array}$ \\
\hline
\end{tabular}

Random effects panel regressions, standard errors adjusted for clustering at the session level. Unit of observation: participant-period.

Significance levels: ${ }^{*} \mathrm{p}<0.1,{ }^{* *} \mathrm{p}<0.05,{ }^{* * *} \mathrm{p}<0.01$.

Dependent variable: Shares held at end of period.

Independent variables: Constant: FL. SE, TE, SO: dummies for mental type; \# Lottery choices: number of times a participant chose the lottery over the certain amount in the Holt-Laury task. 


\section{References}

Baghestanian, Sascha, Volodymyr Lugovskyy, and Daniela Puzzello. 2012. Individual behavior in experimental asset markets: theory and evidence. Technical report. Tech. rep., Working Paper, University of Indiana.

Baghestanian, Sascha, Volodymyr Lugovskyy, Daniela Puzzello, and Steven Tucker. 2014. "Trading Institutions in Experimental Asset Markets: Theory and Evidence."

Bock, Olaf, Ingmar Baetge, and Andreas Nicklisch. 2014. "hroot: Hamburg registration and organization online tool." European Economic Review 71:117-120.

Bosch-Rosa, Ciril, Thomas Meissner, and Antoni Bosch-Domènech. 2015. Cognitive Bubbles. Discussion Paper, SFB 649 2015-006.

Boswijk, H. Peter, Cars H. Hommes, and Sebastiano Manzan. 2007. "Behavioral heterogeneity in stock prices." Journal of Economic Dynamics and Control 31, no. 6 (June): 1938-1970. ISSN: 01651889.

Breaban, Adriana, and Charles N Noussair. 2015. "Trader characteristics and fundamental value trajectories in an asset market experiment." Journal of Behavioral and Experimental Finance 8:1-17.

Bruguier, Antoine J, Steven R Quartz, and Peter Bossaerts. 2010. "Exploring the Nature of "Trader Intuition"." The Journal of Finance LXV (5): 1703-1724.

Camerer, Colin F, Teck-Hua Ho, and Juin-Kuan Chong. 2004. "A cognitive hierarchy model of games." The Quarterly Journal of Economics: 861-898. 
Corgnet, Brice, Roberto Hernán-gonzalez, Praveen Kujal, and David Porter. 2013. "The Effect of Earned vs. House Money on Price Bubble Formation in Experimental Asset Markets." Unpublished mimeo.

Coricelli, Giorgio, and Rosemarie Nagel. 2009. "Neural correlates of depth of strategic reasoning in medial prefrontal cortex." Proceedings of the National Academy of Sciences of the United States of America 106, no. 23 (June): 9163-8. ISSN: 1091-6490.

Cueva, Carlos, and Aldo Rustichini. 2015. "Is financial instability male-driven? Gender and cognitive skills in experimental asset markets." Journal of Economic Behavior E Organization 119:330-344.

De Long, J Bradford, Andrei Shleifer, Lawrence H Summers, and Robert J Waldmann. 1990. "Noise trader risk in financial markets." Journal of political Economy: 703-738.

De Martino, Benedetto, John P O’Doherty, Debajyoti Ray, Peter Bossaerts, and Colin Camerer. 2013. "In the mind of the market: theory of mind biases value computation during financial bubbles." Neuron 79, no. 6 (September): 1222-31. ISSN: 1097-4199.

Fischbacher, Urs. 2007. "z-Tree: Zurich toolbox for ready-made economic experiments." Experimental Economics 10 (2): 171-178. ISSN: 1386-4157, accessed August 7, 2012.

Frederick, Shane. 2005. "Cognitive Reflection and Decision Making." Journal of Economic Perspectives 19, no. 4 (December): 25-42. ISSN: 0895-3309.

Frith, Chris D, and Tania Singer. 2008. "The role of social cognition in decision making." Philosophical Transactions of the Royal Society B: Biological Sciences 363 (1511): $3875-3886$.

Grinblatt, Mark, Matti Keloharju, and Juhani Linnainmaa. 2011. "IQ and stock market participation." The Journal of Finance 66 (6): 2121-2164. 
Hanaki, Nobuyuki, Eizo Akiyama, Yukihiko Funaki, and Ryuichiro Ishikawa. 2015. Diversity in cognitive ability enlarges mispricing. Working Paper, GREDEG 2015-29.

Hefti, Andreas, Steve Heinke, and Frederic Schneider. 2016. "Online Material for 'Mental Capabilities, Trading Styles, and Asset Market Bubbles: Theory and Experiment'."

Hellwig, Martin F. 1980. "On the aggregation of information in competitive markets." Journal of economic theory 22 (3): 477-498.

Holt, Charles A, and Susan K Laury. 2002. "Risk aversion and incentive effects." American economic review 92 (5): 1644-1655.

Hommes, Cars. 2011. "The heterogeneous expectations hypothesis: Some evidence from the lab." Journal of Economic Dynamics and Control 35 (1): 1-24. ISSN: 0165-1889.

Janssen, Dirk-Jan, Utz Weitzel, and Sascha Füllbrunn. 2015. Speculative Bubbles - An introduction and application of the Speculation Elicitation Task (SET). Paper 63028. MPRA, March.

Kaizoji, Taisei, Matthias Leiss, Alexander Saichev, and Didier Sornette. 2015. "Superexponential endogenous bubbles in an equilibrium model of fundamentalist and chartist traders." Journal of Economic Behavior \& Organization 112:289-310.

Keynes, John Maynard. 1936. The General Theory of Employment, Interest and Money. Reprinted 2007. London: Palgrave Macmillan.

Korniotis, George M, and Alok Kumar. 2010. "Cognitive abilities and financial decisions." Behavioral Finance: 559-576.

Kyle, Albert S. 1985. "Continuous auctions and insider trading." Econometrica: Journal of the Econometric Society: 1315-1335. 
Kyle, Albert S. 1989. "Informed speculation with imperfect competition." The Review of Economic Studies 56 (3): 317-355.

Levine, Sheen S, Mark Bernard, and Rosemarie Chariklia Nagel. 2015. "Know Thyself, Know Thy Rival: Experimental Evidence on How Strategic IQ Benefits Performance." In Academy of Management Proceedings, 2015:11121. 1. Academy of Management.

Luik, Marc-André, and Max Friedrich Steinhardt. 2015. Immigrant-native differences in stockholding: The role of cognitive and non-cognitive skills. Research Paper 164. HWWI.

McKelvey, Richard D, and Thomas R Palfrey. 1995. "Quantal response equilibria for normal form games." Games and economic behavior 10 (1): 6-38.

McKinney Jr, C Nicholas, and John B Van Huyck. 2006. "Does seeing more deeply into a game increase one's chances of winning?" Experimental economics 9 (3): 297-303.

Noussair, Charles N, Steven James Tucker, and Yilong Xu. 2014. A Futures Market Reduces Bubbles But Allows Greater Profit for More Sophisticated Traders. Discussion Paper 2014-051.

Palan, Stefan. 2015. "GIMS - Software for asset market experiments." Journal of Behavioral and Experimental Finance 5:1-14.

Premack, David, and Guy Woodruff. 1978. "Does the chimpanzee have a theory of mind?" Behavioral and brain sciences 1 (04): 515-526.

Reniers, Renate LEP, Rhiannon Corcoran, Richard Drake, Nick M Shryane, and Birgit A Völlm. 2011. "The QCAE: A questionnaire of cognitive and affective empathy." Journal of personality assessment 93 (1): 84-95. 
Shiller, Robert J. 2015. Irrational exuberance. 3rd ed. Princeton University Press.

Smith, Alec, Terry Lohrenz, Justin King, P Read Montague, and Colin F Camerer. 2014. "Irrational exuberance and neural crash warning signals during endogenous experimental market bubbles." Proceedings of the National Academy of Sciences 111 (29): 10503-10508.

Smith, Vernon L, Gerry L Suchanek, and Arlington W Williams. 1988. "Bubbles, crashes, and endogenous expectations in experimental spot asset markets." Econometrica: Journal of the Econometric Society: 1119-1151.

Soros, George. 2003. The alchemy of finance. John Wiley \& Sons.

Stahl, Dale O, and Paul W Wilson. 1995. "On players models of other players: Theory and experimental evidence." Games and Economic Behavior 10 (1): 218-254.

Van Overwalle, Frank, and Kris Baetens. 2009. "Understanding others' actions and goals by mirror and mentalizing systems: a meta-analysis." Neuroimage 48 (3): 564-584.

Zuckerman, Gregory. 2000. "Hedged Out: How the Soros Funds Lost Game of Chicken Against Tech Stocks." Wall Street Journal (May). 


\section{Appendix}

\subsection{Proof of Proposition 1}

Define $\varepsilon_{\theta, \theta^{\prime}} \equiv \varepsilon_{\theta}-\varepsilon_{\theta^{\prime}}$ and $Z_{j}^{\theta, \theta^{\prime}} \equiv \varphi_{j}\left(r_{j}^{\theta}, X_{j}\right)-\varphi_{j}\left(r_{j}^{\theta^{\prime}}, X_{j}\right), X_{1}=F, X_{2}=P$. By the valuation equation (4') we have

$$
\begin{aligned}
& \operatorname{Pr}(F L)=\operatorname{Pr}\left(\varepsilon_{F L, S E}<Z_{2}^{F L, S E}, \varepsilon_{F L, T E}<Z_{1}^{F L, T E}, \varepsilon_{F L, S O}<Z_{1}^{F L, S O}+Z_{2}^{F L, S O}\right) \\
& \operatorname{Pr}(S E)=\operatorname{Pr}\left(\varepsilon_{S E, F L}<Z_{2}^{S E, F L}, \varepsilon_{S E, T E}<Z_{1}^{S E, T E}+Z_{2}^{S E, T E}, \varepsilon_{S E, S O}<Z_{1}^{S E, S O}\right) \\
& \operatorname{Pr}(T E)=\operatorname{Pr}\left(\varepsilon_{T E, F L}<Z_{1}^{T E, F L}, \varepsilon_{T E, S E}<Z_{1}^{T E, S E}+Z_{2}^{T E, S E}, \varepsilon_{T E, S O}<Z_{2}^{T E, S O}\right) \\
& \operatorname{Pr}(S O)=\operatorname{Pr}\left(\varepsilon_{S O, F L}<Z_{1}^{S O, F L}+Z_{2}^{S O, F L}, \varepsilon_{S O, S E}<Z_{1}^{S O, S E}, \varepsilon_{S O, T E}<Z_{2}^{S O, T E}\right)
\end{aligned}
$$

The effects of $d F, d P$ on $\operatorname{Pr}(\theta \mid F, P)$ as stated in table 1 then follow from (9), noting that, by supermodularity, $\frac{\partial Z_{j}^{\theta, \theta^{\prime}}}{\partial X_{j}}>0$ iff $r_{j}^{\theta}>r_{j}^{\theta^{\prime}}$. 


\subsection{Split along each Dimension and Trading Gains}

Figure 7: Trading gains across cognitive types.

(a) Trading gains across one dimension

(b) Trading gains across all four types
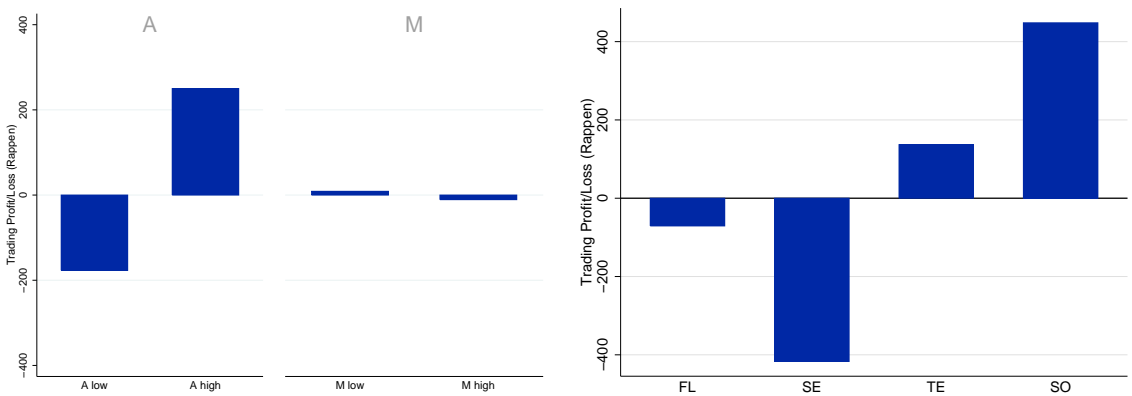

On the vertical axis, we plot trading income over the entire duration of the asset market for the baseline treatments $(\mathrm{N}=256)$. Panel (a) shows both the median split along to the A dimension (left side) and along the $\mathrm{M}$ dimension (right side). Viewed in isolation, the $\mathrm{A}$ dimension shows a substantial difference in trading gains/losses, while the $\mathrm{M}$ dimension does not seem to predict trading success. Panel (b) displays the four different types and uncovers great heterogeneity. The semiotic type incurs most of the losses while the sophisticated type earn most of the profits and the featureless types as well as the technocrats earn zero profits. 